\title{
Cartografiar el espacio salitrero: El "descampado de Atacama" y de Tarapacá en las representaciones cartográficas antes y durante el ciclo del nitrato (siglos XVIII-XX)*
}

\author{
Mapping the saltpeter space: The "descampado de Atacama" and Tarapacá in \\ cartographic representations before and during nitrate cycle (18th-20th century)
}

\author{
Pablo Artaza Barrios** \\ Diego Lizama Gavilán ${ }^{* * *}$
}

\section{RESUMEN}

Entre los siglos XVIII y XX se desarrolló una infinidad de representaciones cartográficas del descampado o desierto de Atacama y de Tarapacá como región líder en la producción de salitre. En ese sentido y siguiendo una conceptualización nacida desde la geografía crítica y la cartografía histórica, el presente trabajo tiene como finalidad analizar de manera expositiva y descriptiva la producción cartográfica de esos territorios, resaltando sus características más importantes y el contexto en que se produjeron.

Palabras clave: Descampado de Atacama, Tarapacá, producción del espacio, industria del salitre, cartografía

\section{ABSTRACT}

Between the 18th and 20th centuries, an infinite number of cartographic representations of the open ground or Atacama Desert and Tarapacá developed as a leading region in the production of nitrate. In this sense, and following a conceptualization born from critical geography and historical cartography, the purpose of this work is to analyze in an expository and descriptive way the cartographic production of those territories, highlighting their most important characteristics and the context in which they were produced.

Key words: Deserted of Atacama, Tarapacá, production of space, saltpeter industry, cartography

Recibido: febrero 2021

Aceptado: mayo 2021

\footnotetext{
* Artículo desarrollado en el marco del Proyecto FONDECYT Regular № 1171198 y № 1190303.

** Académico del Departamento de Ciencias Históricas de la Universidad de Chile, Chile. ORCID: https://orcid.org/0000-0001-5724-5605. Correo electrónico: partaza@uchile.cl.

*** Magister (c) en Historia, Universidad de Chile, Chile. ORCID: https://orcid.org/0000-0001-7627-6271. Correo electrónico: diegolizama@ug.uchile.cl.
} 


\section{Introducción: territorio, espacio y capitalismo}

Una de las necesidades principales del sistema capitalista -con sus formas particulares de acumulación-, fue la de reconocer los territorios en que se podían desarrollar mecanismos productivos para explotar materias primas que sustentaran la creciente demanda del comercio mundial, sobre todo en un amplio período de tiempo (siglos XVIII, XIX y XX) en que Europa se transformó en el centro de consumo de esas materias primas y de manufactura de bienes $y$ servicios, lo que para el caso mundial Wallerstein ha denominado como el desarrollo del capitalismo histórico ${ }^{1} \mathrm{y}$, en el caso específico de Chile, aunque tomando distancia crítica respecto de la teoría de la dependencia que tanta importancia cobrara en América Latina ${ }^{2}$, Carmagnani y Ortega, han identificado como un desarrollo industrial con características de dependencia y un subdesarrollo económico y material basado en la inversión de capitales extranjeros y en el cobro de impuestos a la exportación por parte del Estado ${ }^{3}$.

Dicha necesidad económica de definir los territorios explotados originó, además, la necesidad política de definir, limitar y, por tanto, controlar esos territorios a través de su división administrativa, lo que produjo una conjunción entre los intereses privados y públicos a través de la formación de los Estados nacionales, llevando a los países a involucrarse en guerras internas y externas en torno a la definición de límites y la ocupación de extensos territorios ${ }^{4}$.

Lo anterior, por supuesto, se sumó a la forma tradicional en que los grupos humanos entendieron el territorio habitado, produciéndose espacialidades o territorialidades específicas que diferenciaron a un grupo social de otro en pequeñas localidades o en amplias regiones, formas de habitar que generaron resistencias frente al capitalismo y, en más de alguna ocasión, profundas contradicciones entre las necesidades económico-políticas y el devenir de las sociedades que fueron intervenidas por las formas modernas de producción y la creciente industrialización y tecnificación de los territorios ${ }^{5}$.

\footnotetext{
${ }^{1}$ Wallerstein, Immanuel. 2014. El capitalismo histórico, Madrid, Siglo XXI.

2 Para una profundización respecto de la génesis, alcances, principales corrientes y cultores de la teoría de la dependencia en América Latina resulta especialmente útil el texto de uno de sus representantes, Dos Santos, Theotonio. 2002. La teoría de la dependencia. Balance y perspectivas, México, Plaza y Janés.

${ }^{3}$ Carmagnani, Marcello. 1998. Desarrollo industrial y subdesarrollo económico. El caso chileno (1860-1920), Santiago, DIBAM, Departamento de Ciencias Históricas de la Universidad de Chile, Centro de Investigación Diego Barros Arana; Ortega, Luis. 2005. Chile en ruta al capitalismo: cambio, euforia y depresión 1850-1880, Santiago, Lom Ediciones.

4 Valencia, Germán. 2011. "Teoría económica y formación del Estado nación: mercantilistas y liberalistas", en Ecos de Economía, Vol. 15, № 32, Medellín, pp. 1-23; Godoy, Milton. 2018. “¿Un gigante con pies de barro? Estado y región en Chile: Atacama meridional (Taltal), 1850-1900”, en Godoy, Milton. 2018. La puerta del desierto: Estado y región en Atacama. Taltal, 1850-1900, Santiago, Editorial Mutante, pp. 43-88.

5 Marchioni, Marco. 2013. "Espacio, territorio y procesos comunitarios", en Revista Espacios Transnacionales, № 1, México, pp. 92-100; Pfeilstetter, R. 2011. "El territorio como sistema social autopoiético. Pensando en alternativas teóricas al 'espacio administrativo' y a la 'comunidad local'", en Perifèria: revista de recerca i formació en
} 
Estas contradicciones, que emanaron de la relación entre los sistemas económicos, la imposición estatal, las comunidades locales y las permanentes migraciones, fueron el estímulo principal para que las elites favorecieran la producción de conocimientos necesarios para controlar la transformación del territorio y facilitaran la dominación social.

Las áreas técnicas y científicas que lo produjeron fueron disciplinas como la geografía, la hidrografía, la geología, la mineralogía y la cartografía, entre otras, siendo esta última la preocupada de graficar aquellos territorios estudiados por el resto de estas ciencias. Aunque resulta evidente la necesidad de dejar en claro que lo anterior no descarta el desarrollo de estas áreas del conocimiento humano como procesos intelectuales emanados de la natural curiosidad y entendimiento humano. Sin embargo, sí es preciso enfatizar en que han sido funcionales a las necesidades de los sistemas económicos hegemonizantes. Estas disciplinas, durante parte importante de los siglos XIX y XX, crearon paradigmas basados particularmente en el estudio de los aspectos físicos del territorio, paradigmas positivistas si se quiere, dejando fuera el entendimiento del espacio como un proceso social y en el que intervinieron las colectividades e individualidades, sobre todo en lo que respecta al desarrollo del capitalismo, sus dinámicas de acumulación particulares y las prácticas sociales que proceden de él ${ }^{6}$.

Aunque también hubo producción de conocimiento científico y disciplinar que estuvo al servicio de las intenciones y necesidades derivadas del imperialismo europeo, que se revitalizaron en la segunda década del siglo XIX y buscaron influir directamente en las sociedades criollas que habían logrado independizarse de España. Esto implicó un importante despliegue, tanto marítimo como terrestre, de expediciones que recorrieron territorios y espacios sociales donde -a través del ejercicio científico, de análisis, observación, producción de literatura y debates en instituciones académicas - se redescubrieron importantes recursos naturales, lo que tuvo un significativo impacto económico y político hasta inicios del siglo XX7.

En este sentido, para Henri Lefebvre parte importante del proceso que él denomina producción del espacio social se da también a partir de la acumulación de estos conocimientos, pues, para este autor, el territorio, gracias a su especificidad material, es por sí solo una

antropología, № 14, Barcelona, pp. 1-17; y González, Sergio. 2009. "El Norte Grande de Chile: la definición histórica de sus límites, zonas de líneas de fronteras, y la importancia de las ciudades como geosímbolos fronterizos", en Revista de Historia Social y de las Mentalidades, Vol. 13, № 2, Santiago, pp. 1-25.

${ }^{6}$ Beltrán, Santos. 2013. "Espacio y capitalismo: la crisis capitalista, el territorio y las resistencias sociales", en Ciencia Política, Vol. 8, № 16, Bogotá, pp. 138-167.

7 Turner, Frank. 1980. "Public Science in Britain, 1880-1919”, en Isis, Vol. 71, № 4, Chicago, pp. 589-608; Palladino, Paolo y Wordboys, Michael. 1993. "Science and Imperialism", en Isis, Vol. 84, № 1, Chicago, pp. 91-102; Sluyter, Andrew. 2001. "Colonialism and Landscape in the Americas: Material/Conceptual Transformations and Continuing Consequences", en Annals of the Association of American Geographers, Vol. 91, № 2, Baton Rouge, pp. 410-428; Baber, Zaheer. 2001. "Colonizing nature: scientific knowledge, colonial power and the incorporation of India into the modern world system", British Journal of Sociology, Vol. 52, No. 1, pp. 37-58; Mayo, John. 1981. "Britain and Chile. Anatomy of a relationship", en Journal of Interamerican studies and world and affairs, Vol. 23, № 1, Londres, pp. 95120. 
herramienta de producción de conocimiento, ya que sus formas entregan información visual mucho antes de que los grupos humanos necesiten analizarlo y estudiarlo, para luego hacer uso de él y transformarlo. Como señala Ovidio Delgado, siguiendo a Lefebvre y otros expositores de la geografía radical, el espacio cartografiado "es considerado como un producto del modo de producción, y su comprensión requiere el conocimiento de la forma como opera dicho modo de producción, como proceso histórico-geográfico. Los cambios espaciales obedecen a los ajustes necesarios que cada modo de producción debe hacer en la organización del espacio para garantizar su propia producción. Así, por ejemplo, la expansión o ampliación de las áreas de mercado, la colonización y el imperialismo, la globalización y la conformación de bloques económicos y zonas de mercado libre, la relocalización de la producción y de la fuerza laboral, entre otras, son estrategias espaciales que el capitalismo ha utilizado a lo largo de su historia para constituirse y mantenerse como sistema hegemónico. La conquista espacial del capitalismo es clave en el fortalecimiento y consolidación del capitalismo, pues le ha permitido, en buena medida, la solución de sus crisis periódicas de acumulación" ${ }^{8}$.

Estos conocimientos -sean básicos o ampliados con detalle por las disciplinas anteriormente señaladas-forman una imaginabilidad territorial cargada de significantes y significados, a través de los cuales las sociedades dan contenido y sustancia a los hitos geográficos, a las formas en sí, y permiten la construcción de caminos, ferrocarriles y puentes, dando vida a la industria, los pueblos y ciudades, en definitiva, produciendo espacio donde antes solo había territorio material. En el caso de los sistemas económicos ya nombrados -basados en la acumulación y la reinvención tecnológica-el territorio transformado en espacio no solo se utiliza para satisfacer las necesidades básicas de los individuos, sino que, además, se le entrega valor de uso y de cambio, vendible, intercambiable y explotable, convirtiéndose por tanto en un territorio capitalizado 9 .

Uno de los problemas importantes que se presenta a la hora de analizar la implementación del capitalismo y sus formas de extracción de recursos naturales, es el cambio en el entendimiento de los sujetos del propio territorio habitado, e incluso, previamente explotado.

El desarrollo de mecanismos tecnificados para lograr la extracción de recursos cambió de manera radical durante los siglos XVIII y XIX, propiciado por dos importantes procesos de industrialización a nivel mundial. En torno a la idea de capitalización del espacio, es preciso decir que, en ese contexto de producción, circulación e intercambio internacional, el espacio geográfico fue visto como objeto; visto en su dimensión material desde una perspectiva exógena -empresas extranjeras que invierten capital para la producción en espacios geográficos y sociales resignificados- generándose transformaciones en la forma de

\footnotetext{
8 Delgado, Ovidio. 2003. Debates sobre espacio en la geografía contemporánea, Bogotá, Universidad Nacional de Colombia, pp. 81 y siguiente.

${ }^{9}$ Lefebvre, Henri. 1974, “La producción del espacio”, en Papers. Revista de Sociología, № 3, Barcelona, pp. 219-229.
} 
comprender la relación entre la sociedad y la naturaleza, tal y como las presenta Adrián Zarrilli, quien califica este cambio de catastrófico en la medida que la producción capitalista profundiza la destrucción medio ambiental, al imponer una lógica economicista para entender el territorio, por sobre el entendimiento del mismo desde la dualidad histórico-cultural en que se basa tanto la relación sociedad-naturaleza e individuo-naturaleza, donde intermedian formas de trabajo, saberes específicos, recursos y medios de producción adaptados localmente al entorno, los que se ven condicionados por los sistemas económicos y de producción. Existe por tanto una disociación destructiva, en la medida en que se extraen recursos, pero también una asociación creativa, puesto que el capitalismo produce bienes comerciables que antes no existían. Es, por tanto, una relación dialéctica ${ }^{10}$.

Al respecto, en Latinoamérica como también en Chile, se registró la implementación de formas productivas externas con caracteres culturales específicos, las que a través de mecanismos tanto formales como informales, generaron una relación de interdependencia entre el centro económico y la periferia proveedora de recursos ${ }^{11}$. Como se verá más adelante, el conocimiento de los territorios explotados y el consiguiente desarrollo de su cartografía, permitieron a las economías centrales, marcadas principalmente por el desarrollo de un imperialismo territorial, económico y también científico, en el que destacó principalmente Gran Bretaña y su institucionalidad especializada -productora y conservadora de conocimiento- ${ }^{12}$, explotar territorios alejados como el sur de Chile, en el caso del carbón, o tan inhóspitos como el desierto de Atacama, para transformar recursos como el salitre en abono para las tierras agrícolas europeas y otras partes del mundo ${ }^{13}$.

Como señalan Morales, Richard y Garcés, el desierto de Atacama fue un lugar bastante especial para la inserción del capitalismo extractivista del siglo XIX, puesto que:

"se transformó muy precozmente en un laboratorio de formas muy avanzadas de capitalismo extractivo y esta orientación vanguardista o futurista es un rasgo que se mantiene en la actualidad: Chuquicamata, la minería del litio, el tren de Caldera a Copiapó, la termoeléctrica de Tocopilla, María Elena, los telescopios astronómicos, Humberstone, etc., son todas figuras vanguardistas. Muchísimas cosas -la electricidad, el movimiento obrero, los primeros camiones, las máquinas, los grandes flujos migratorios, la guerra y el

\footnotetext{
10 Zarrilli, Adrián. 2002. "Transformación ecológica y precariedad económica en una economía marginal. El gran Chaco argentino, 1890-1950", en Theomai, № 1, Buenos Aires, pp. 1-14.

11 Thompson, Andrew. 1992. "An exploration in the history of Anglo-Argentine relations, 1810-1914", en Journal of Latin American Studies, Vol. 24, No 2, Londres. pp. 419-436.

12 Llanos, Claudio. 2011. "Pueblos y paisajes en la royal society de Londres. Las ciencias humanas y el imperialismo británico. (1860-1914)", en História, Vol. 30, n. 1, Sao Paulo, pp. 306-331.

${ }^{13}$ Centner, Charles W. 1942. "Great Britain and chilean mining. 1830-1914", en The Economic History Rewiev, Vol. $12, N^{\circ} 1 / 2$, Nueva Jersey, pp. 76-82.
} 
nacionalismo, los conflictos ambientales, la primera vez que alguien se tomó un aviónocurrieron aquí mucho antes que en otras partes"14.

Presentándose además la particularidad de que en el desierto, fuera de los asentamientos tradicionales, todo está por construirse y realizarse, lo que propicia la construcción de puertos, ferrocarriles, se levantan pueblos, se utilizan antiguos y nuevos caminos, se abastece a través de antiguas y nuevas rutas comerciales interregionales e internacionales, se moviliza mano de obra desde tierras lejanas, etc.

De esa forma, es posible señalar que tanto las expediciones científicas como los viajes realizados por comerciantes, militares, intelectuales y otras personalidades de los siglos XVIII y XIX, fueron parte de un esfuerzo tanto por entender la "otredad" de las culturas, como entender los territorios en que habitaban y sobrevivían aquellas sociedades alejadas del hemisferio norte. Así, en la literatura de viajes y la ilustración que describen lo exótico y lo nativo, junto con la cartografía de espacios geográficos lejanos e inhóspitos, la cultura capitalista europea genera una imagen específica que difiere de la propia. La que se ve estimulada por el deseo de ciertos grupos autóctonos -principalmente la elite criolla en posiciones de poder-por adaptar su forma de vida a la del capitalista extranjero, al entroncarse con la necesidad de los foráneos de ejercer dominio económico y político a través de la inversión de capitales, la transformación de los espacios por la habitabilidad, conectividad y productividad, la extracción de recursos y la comercialización de los mismos ${ }^{15}$.

El siglo XIX, en específico, es el siglo en que se consolidan como ciencia "distintas disciplinas vinculadas al estudio de la tierra y su morfología; entre estas, principalmente la Geología, la Geodesia, la Topografía y otras. Y también acontece, en esta época, la consolidación de numerosas otras disciplinas que están estrechamente vinculadas al estudio de la gea, tales como la Meteorología y la Geofísica", y se generan comunidades científicas, academias e instituciones dedicadas a la producción de conocimiento. Conocer el territorio es parte de la búsqueda de progreso en la modernidad y, por ende, en el capitalismo en ciernes ${ }^{16}$.

Retomando una línea de análisis lefebvriano, David Harvey señala la necesidad que poseen los ejecutores de las estructuras económicas y políticas de implementar mecanismos de poder basados en el conocimiento acumulado sobre el territorio y el espacio socialmente utilizado. Estos mecanismos son los encargados de desarrollar posteriormente una fragmentación

\footnotetext{
${ }^{14}$ Morales, Héctor, Richard, Nicolas y Garcés, Alejandro. 2018. “Capitalismo en el desierto: materialidades, espacios y movimiento", en Revista Chilena de Antropología, Universidad de Chile, №37, Santiago, pp. 77.

15 Navarro, Fernando y Fernández, Sandra. 2001. "Viajes y viajeros: sobre algunos tópicos para entender la mirada cultural sobre la economía regional argentina", en Theomai, № 3, Buenos Aires, pp. 1-10; Llanos, Claudio y González, José Antonio. 2014. "Riquezas y rutas. El sur de Chile en la mirada científica imperial británica. (1830-1870)", en Uistória Unisinos, Vol. 18, №1, Sao Lepoldo, pp. 44-55.

16 Saldivia, Zenobio. 2005. La Ciencia en el Chile Decimonónico, Santiago, Ediciones Universidad Tecnológica Metropolitana, pp. 25.
} 
espacial, definiendo elementos como la demografía, la ubicación exacta de los recursos naturales, el clima específico de cada territorio, etc., los que van dando mayor especificidad a los lugares intervenidos por las dinámicas económicas ${ }^{17}$. La cartografía es entonces una representación del poder y por tanto implica una producción del espacio social definida por las intencionalidades de quienes producen el mapa o carta geográfica ${ }^{18}$.

La fragmentación espacial es una de las causas por las que el conocimiento del territorio y del espacio es solamente parcial, y lo vuelve de cierta forma imposible de conocer en su totalidad, idea en la que coinciden tanto Ángel Bassols ${ }^{19}$ como Irma Carrascal $^{20}$. Mientras que Bassols nos habla de la existencia de un territorio difícil de conocer a cabalidad, introduce también el concepto de medio natural, el que define como aquel territorio estudiado, intervenido y adaptado por los seres humanos, es decir el espacio social conocido por las sociedades, excluyendo el territorio por conocer. Carrascal por su parte nos introduce al tema de la cartografía, y señala en específico a los mapas -expresión gráfica del territorio y el espacio-como modelos de realidad inacabados debido a lo anteriormente argumentado por Bassols, es decir, que solo se conoce el medio natural que se habita en un espacio y tiempo determinado.

Ese medio natural es el que provee a los grupos sociales del componente biofísico, forma en la que Mario Sossa Velázquez define a los recursos naturales explotados ${ }^{21}$. El componente biofísico es también reconocido por la geografía y representado por la cartografía de diferentes maneras, sobre todo durante el siglo XIX, período en que la cartografía se tecnifica y mejora notoriamente.

Siguiendo la línea del mapa como expresión inacabada de la realidad, Andrés Núñez, Antonia Zambra y Enrique Aliste señalan que, a partir del ejemplo de la Patagonia y Aysén, las cartas o mapas se constituyen como objetos vaciados y deshumanizados, representando un paisaje sin elementos sociales donde prevalecen los símbolos y referencias económicas, por sobre la representación de grupos humanos y donde las localidades o pueblos son meros geosímbolos de referencia ${ }^{22}$.

Las cartografías, son también objetos técnicos de la modernidad que, de una u otra forma, revelan la transformación del espacio realizada por otros objetos técnicos, en nuestro caso, la

\footnotetext{
${ }^{17}$ Harvey, David. 2007. Espacios del capital. Hacia una geografía crítica, Madrid, Akal Editores.

18 Vega, Alejandra. 2014. Los Andes y el territorio de Chile en el siglo XVI. Descripción, reconocimiento e invención, Santiago, DIBAM, Centro de Investigaciones Barros Arana.

${ }^{19}$ Bassols, Ángel. 1979. Geografía, subdesarrollo y regionalización, México, Editorial Nuestro Tiempo.

${ }^{20}$ Carrascal, Irma. 2007. Metodología para el análisis de mapas. Temas seleccionados de geografía de México, México, Instituto de Geografía UNAM.

${ }^{21}$ Sosa Velázquez, Mario. 2012. ¿Cómo entender el territorio?, Guatemala, Cara Parens.

22 Núñez, Andrés; Zambra, Antonia y Aliste, Enrique. 2017. "El poder de los mapas. los mapas de poder: la construcción del saber geográfico de Patagonia-Aysén”, en Universum, Vol. 32, № 2, Talca, pp. 149-162.
} 
maquinaria productiva del capitalismo decimonónico. Para Milton Santos, por ejemplo, el espacio:

"está formado por objetos técnicos. El espacio del trabajo contiene técnicas que permanecen en él como autorizaciones para hacer esto o aquello, de esta o aquella forma, a este o a aquel ritmo, según esta u otra sucesión. Todo eso es tiempo. El espacio distancia es también modulado por las técnicas que dirigen la tipología y funcionalidad de los desplazamientos. El trabajo supone el lugar, la distancia supone la extensión; el proceso productivo directo está adecuado al lugar; la circulación está adecuada a la extensión. Esas dos manifestaciones del espacio geográfico se unen, así, a través de esas dos manifestaciones en el uso del tiempo" 23 .

Es en el tiempo y el espacio, entonces, donde las técnicas productivas y científicas cartográficas- encuentran su significado, puesto que tienen una funcionalidad específica, y en el caso de los mapas, parte del producto transmisor de conocimiento en un tiempo determinado.

Para J. B. Harley las representaciones cartográficas son documentos históricos formados por ideas, significados ocultos e incluso ficciones que le permiten al cientista social en general y al historiador en particular, estudiar un periodo y espacio de tiempo determinados. Siguiendo a Harley, Rosenblitt y Sanhueza señalan que los mapas son formas de conocimiento y de poder "en la medida que constituyen medios de control sobre un espacio geográfico determinado. Todo en ellos proporciona algún mensaje, tanto la información explícita que entregan como las ausencias deliberadas de ésta" ${ }^{24}$. El mapa es entonces un objeto hermenéutico, interpretable y conocible en la medida que permite la reconstrucción de un relato y el entendimiento de un contexto histórico ${ }^{25}$.

Para Harley, la relación entre conocimiento y poder es fundamental para entender también la relación entre geografía y mapas. En ese sentido, los mapas son "imágenes cargadas de valor" que sirvieron en el siglo XIX -y sirven aún- como abstracción positivista y como mecanismo de poder que imponía una imagen total del mundo, o de regiones del mundo, con intereses creados a partir de necesidades político-productivas. Se deriva de ello, entonces, una imaginación del poder ejercido en el espacio a través de la imposición de un lenguaje cartográfico -los mapas son "un tipo de lenguaje" según el autor-funcional al ejercicio

\footnotetext{
${ }^{23}$ Santos, Milton. 2000. La naturaleza del espacio, Barcelona, Editorial Ariel, pp. 47-48.

${ }^{24}$ Rosenblitt, Jaime y Sanhueza, Ma Carolina. 2010. Cartografía histórica de Chile, 1778-1929. Santiago, Cámara Chilena de la Construcción, Pontificia Universidad Católica de Chile, DIBAM, p. 11.

25 Crespo, Antonio y Fernández, Alberto. 2011. "¿Cartografía antigua o Cartografía histórica?", en Estudios Geográficos, Vol. LXXII, № 271, Madrid, pp. 403-420.
} 
económico y la movilidad de masas humanas para, con su fuerza de trabajo, transformar en riqueza el espacio socialmente producido.

Así también, el mapa es iconográfico y, por tanto, transporta en si mismo un mensaje y conocimiento profundo de aquello que se describe con símbolos: líneas, colores, formas, etc. Por tanto, esa iconografía es la del poder político y económico, del poder público o privado delimitación entre el territorio estatal y el comercial-empresarial-ejercido sobre el territorio, puesto que no se mapea aquello que no es útil para el dominio y para la producción. Luego, la producción cartográfica es una "búsqueda de verdad", en este caso, la verdad territorial, material y física. Por tanto, quien encuentra esa verdad, el componente específico de la formación territorial para su uso administrativo y de producción, puede ejercer el poder, porque es dueño de esa verdad específica. El conocimiento, y en este caso el conocimiento geográfico, está al servicio del poder.

De esta forma, Harley puede relacionar la producción de los mapas en tres etapas distintas, siendo la más abstracta el contexto histórico-político en que se genera un mapa y que va a depender de las etapas de desarrollo de un pueblo, sociedad o cultura en un territorio específico -no es igual un mapa de exploración a uno de guerra, uno de anexión expansiva o productividad, de fuentes fluviales, etc.- y las formas concretas, es decir, la creación de imperios que necesitan conocer los territorios conquistados, y la formación del Estado nación, que necesita también definir su territorio interno pero sobre todo conocer sus límites con otros Estados nacionales. En los dos últimos casos, el mapa o carta geográfica puede expresar la expansión de un Estado nacional -que puede expandirse y formar un imperio-o la contracción de un imperio tras la pérdida de sus posiciones externas y su transformación en Estado nación. Por lo que también en el imperio y el Estado-nación, el reconocimiento de los espacios en que se encuentran los recursos o riquezas naturales, es fundamental, dentro del mapeo ${ }^{26}$.

Es esa misma idea la que plantea Valentina Aliste al señalar que el conocimiento científico, geográfico en específico, es legitimador de los proyectos nacionales, del Estado y de las nacionalidades, da fuerza a los discursos y permite ejercer soberanía -poder-sobre espacios específicos. Ese ejercicio de poder territorial tuvo además un fuerte impacto en la transformación de los sentidos locales y de las identidades territoriales, es decir, transformó culturas y sociedades ${ }^{27}$.

Teniendo en cuenta estas conceptualizaciones, el presente artículo tiene como finalidad realizar un análisis expositivo de algunos ejemplos de diferentes cartas y mapas del desierto de

\footnotetext{
${ }^{26}$ Harley, J. B. 2005. La nueva naturaleza de los mapas. Ensayos sobre la historia de la cartografía. México, Fondo de Cultura Económica.

${ }^{27}$ Aliste Salvo, Valentina. 2014. "Develando el territorio para la nación: el saber geográfico como herramienta de control, racionalización y ocupación del territorio mapuche en el siglo XIX", en Boletín Electrónico de Geografía (BeGEO), N² 2, Instituto de Geografía, Facultad de Historia, Geografía y Ciencia Política, Santiago, pp. 1-17.
} 
Atacama y en específico de la región de Tarapacá -antiguo territorio peruano que posteriormente quedó bajo dominio chileno tras la Guerra del Pacífico-producidos entre fines del siglo XVIII, el siglo XIX y principios del siglo XX, poniendo énfasis en estos últimos y gracias a lo cual es posible evidenciar, tanto la transformación operada sobre el espacio salitrero, como las distintas expresiones que históricamente fue adoptando la incorporación de este territorio como espacio socialmente producido, ya sea a sus respectivos Estados nacionales como especialmente a la economía dominante a la que se reportaba.

Así, estos mapas y cartas sirvieron primero como fuente de conocimiento para el Estado colonial español y luego también durante los procesos de construcción de los Estados nacionales tanto en los actuales territorios de Perú y Chile, facilitando la instauración del mercantilismo primero, o capitalismo de guerra al decir de Sven Beckert ${ }^{28}$, y del capitalismo y la industrialización del desierto después. En este último caso, nos interesan las cartas geográficas producidas durante el ciclo de expansión y crisis de la industria del salitre, que comenzó bajo administración peruana, pero que fue potenciado por el Estado chileno y la inversión extranjera desde 1880 y hasta 1929.

Interesa también en este artículo dar cuenta de las cartografías atacameñas como documentos que nos permitan leer el pasado histórico del desierto, las sociedades que en él se desarrollaron y la evolución de los sistemas productivos modernos que se impusieron allí donde otros solo vieron descampado. Además, pretendemos abandonar la idea del mapa como mera imagen que permite la geolocalización de hitos y lugares para contextualizar relatos de otros estudios. Es decir, nos interesa dar cuenta de la importancia de las cartas y mapas como documentos abstractos, con discursividad propia en base a su tecnificación progresiva y su utilidad como herramienta intelectual en el ejercicio del poder, sea este colonial, expansionista y nacionalista, o imperialista. En ese sentido, entendemos la cartografía como parte del proceso de producción social del espacio y como fenómeno social en sí mismo, en la medida que permite entender el pensamiento político, económico y social de quienes la produjeron y para quienes se produjeron.

Una segunda parte de esta investigación fue desarrollada en otro trabajo titulado "Producción del espacio, cartografía y relaciones sociales: Tarapacá y Antofagasta durante el ciclo salitrero (1892-1929)" en el que, además de analizar algunas cartas salitreras, se integró una propuesta de cartografía social en la que se buscó ejemplificar fenómenos sociales de circulación, control social y resistencia en el marco de la expansión capitalista en el desierto y pampa del Tamarugal durante el ciclo del nitrato ${ }^{29}$.

\footnotetext{
28 Beckert, Sven. 2015. El imperio del algodón. Una historia global. Barcelona, Editorial Crítica.

29 Artaza, Pablo; Lizama, Diego y Sandoval, Ivo. 2021. "Producción del espacio, cartografía y relaciones sociales: Tarapacá y Antofagasta durante el ciclo salitrero (1892-1929)”, en Diálogo Andino, № 66, Arica.
} 


\section{Representaciones cartográficas del descampado o despoblado de Atacama y Tarapacá antes del ciclo de expansión del nitrato}

Llevar a cabo un catastro de la cartografía del desierto de Atacama y del territorio de Tarapacá en particular, desde el período colonial hasta las primeras tres décadas del siglo XX, es una tarea formidable que implicaría el desarrollo y publicación de varios volúmenes que recopilen dicha producción técnico-intelectual. Lo anterior, se ampliaría contando también con el análisis de aquellas cartografías que fueron acompañadas por diversos estudios geográficos, mineralógicos, hidrológicos, etc. Sin embargo, al realizar una revisión selectiva de cartas o mapas de dicho período, es posible determinar ciertas líneas de análisis y estudio que dan luces tanto de las intencionalidades de quienes las produjeron, como de las relaciones que se establecieron por medio de ellas entre el conocimiento geográfico y la expansión capitalista.

Existen varias experiencias de recopilación cartográfica que avanzaron en esa tarea durante el siglo XIX, como la de Ezequiel Uricoechea y su Mapoteca Colombiana, donde se incluye el mapa de Tarapacá (provincia de Moquegua) producido por William Bollaert y George Smith en $1850^{30}$, o el Ensayo de mapoteca chilena de José Toribio Medina, donde se incluye una amplia variedad de mapas de Chile, Perú y del continente americano, donde Tarapacá aparece delimitada como provincia o como componente de la provincia peruana de Moquegua ${ }^{31}$. Dichas compilaciones permiten abordar el tema de manera más despejada y dan luces también de algunos elementos comunes que desarrollaron los cartógrafos al momento de representar el actual Norte Grande de Chile.

En ese sentido, este apartado intentará presentar una descripción cronológico-analítica de algunas representaciones geográficas a modo de ejemplo, poniendo especial énfasis en aquellas que incluyeron o se centraron específicamente en el desierto de Atacama y el territorio de Tarapacá32.

Pero antes de comenzar con aquello, es necesario explicar los términos "descampado" o "despoblado", ambos utilizados para referir al actual desierto de Atacama, pues ambos conceptos fueron utilizados indistintamente en la documentación oficial y no oficial durante el dominio español sobre los actuales territorios del Sur del Perú, Suroeste de Bolivia, Noroeste de Argentina y Norte de Chile entre los siglos XVIII al XIX. A través de ellos se buscó definir aquellos territorios o regiones difusas para la jurisdicción colonial y poco exploradas por la

\footnotetext{
30 Uricoechea, Ezequiel. 1860. Mapoteca colombiana: Coleccion de los títulos de todos los mapas, planos, vistas, etc. relativos á la América española, Brasil é islas adyacentes, Londres, Trübner \& Cie.

${ }^{31}$ Medina, José Toribio. 1889. Ensayo acerca de una mapoteca chilena ó sea de una colección de los títulos de los mapas, planos y vistas relativos á Chile arreglados cronológicamente: con una introducción histórica acerca de la geografía y cartografía del pais, Santiago, Editorial Ercilla.

32 Villalobos, Sergio. 1979. La economía de un desierto: Tarapacá durante la Colonia, Santiago, Ediciones Nueva Universidad.
} 
metrópoli, generándose una imaginabilidad homogénea de los mismos, sin tomar en cuenta que los ecosistemas, recursos y grupos humanos que los habitaron eran diametralmente distintos entre sí, siendo el desierto solo una parte de ese paisaje. Además, a pesar de las grandes riquezas minerales que albergó, fueron pocos los que se atrevieron a recorrer el desierto, manteniéndose la idea de desolación y despoblamiento al interior de las culturas sudamericanas poscoloniales, por lo que ambos conceptos se mantuvieron en uso tras los procesos de independencia de estos cuatro países ${ }^{33}$.

Si bien las representaciones y aproximaciones geográficas y cartográficas no son un producto eminentemente capitalista en su variante decimonónica, y los orígenes de los mapas se remontan incluso a la antigüedad, si lo son como elementos constituyentes de la modernidad europea desde los siglos XVI al XVIII, sobre todo para los imperios que tuvieron dominio sobre territorios de ultramar -como España en América- y que se vieron en la necesidad de conocer espacios geográficos desconocidos e "inexplorados". Sin embargo, los alcances de esos esfuerzos fueron limitados y en muchos casos insatisfactorios para los fines que se perseguían, puesto que los recursos eran escasos y la tecnología insuficiente como para desarrollar trabajos técnicos de esa amplitud y complejidad ${ }^{34}$. Tal es el caso de las expediciones de Antonio Córdova y Lasso de la Vega (1785-1789) y de Alessandro Malaspina (1789-1794), ambas en el marco de las reformas borbónicas españolas que buscaron ejercer mayor poder político, económico y militar sobre el continente y sus virreinatos, limitándose a cartografiar algunos espacios específicos de Sudamérica y la costa occidental del Pacífico Sur ${ }^{35}$.

Fue solo a mediados del siglo XIX, gracias al avance del empresariado minero y la movilización de la población indígena relativamente próxima y del peonaje rural como mano de obra industrial, del desarrollo de las primeras expediciones científicas contratadas por los gobiernos republicanos y de la acción permanente de grupos trashumantes de arrieros andinos, que el desierto cobró nueva importancia y pasó de ser un territorio agreste, indómito y estéril, a un territorio en disputa por la cuantía de sus recursos, tensionado por la necesidad de definir las fronteras nacionales, regular el desarrollo económico aprovechando el cobro de impuestos $y$, por tanto, pasar a ser un espacio producido y transformado por la racionalidad humana, la tecnología moderna y las relaciones de producción industrial-capitalista que allí se conformaron, convirtiéndose en el Norte Grande de Chile tras la Guerra del Pacífico ${ }^{36}$.

\footnotetext{
${ }^{33}$ González, Sergio. 2013. "Del descampado de Atacama a la sociedad del salitre. Balance y perspectiva en el estudio del ciclo de expansión del nitrato", en González, Sergio comp., La sociedad del salitre. Protagonistas, migrantes, cultura urbana y espacios públicos, 1870-1940, Santiago, Ril Editores, pp. 23-37.

${ }^{34}$ Crespo, Antonio y Fernández, Alberto. 2011. “¿Cartografía antigua o cartografía histórica?”, pp. 403-420.

35 González, José. 2007. "Primeros levantamientos cartográficos generales de Chile con base científica: los mapas de Claudio Gay y Amado Pissis", en Revista de Geografía del Norte Grande, № 38, Antofagasta, pp. 21-44.

${ }^{36}$ González, Sergio. 2013. "Del descampado de Atacama a la Sociedad del Salitre. Balance y perspectiva en el estudio del ciclo de expansión del nitrato"; González, Sergio. 2013. "Heterotopía y utopía en la pampa salitrera. Desde los
} 
Aún teniendo en cuenta lo anterior, lo primero que debemos señalar respecto a la cartografía colonial ${ }^{37}$ es que, si bien sus técnicas y recursos fueron mínimos, su producción en número fue bastante $a_{m p l i a}{ }^{38}$. Sólo en la Mapoteca de la Biblioteca Nacional de Chile incluyendo la Mapoteca de José Toribio Medina- es posible encontrar mapas de los siglo XVII y XVIII, destacando entre ellos, por ejemplo, la Carta del Pacífico y de las Costas de América de Juan Martínez (1600), la Carta particolare della costa del Peru parte Autrale con parte di Chili (1646) sin autor identificado, la Carta esférica de una parte de la costa del Perú, de Antonio Cornel (1791) que incluye el territorio que va desde Arica hasta Pabellón de Pica, la Carta esférica de las costas del Reyno de Chile (1790) también sin autor conocido, el Plan de la Rade de Arica: scituée a la Côte du Perou par 18d 29' de la Australe de la misión geográfica de Amadée Frezier (1716), y las cartas producidas por las expediciones de Antonio Córdova y Lasso de la Vega (1785-1789), y de Alessandro Malaspina (1789-1794) ${ }^{39}$.

La mayor parte de este material cartográfico representó al desierto de Atacama o parte de él, pero al ser solo trabajos de reconocimiento, poseen simbología y descripción para detallar solo algunas localidades importantes, las costas, los ríos y algo de los valles de la depresión intermedia o pampa del Tamarugal en el caso de Tarapacá, además de que no definieron límites o fronteras claras respecto a las posesiones que posteriormente fueron disputadas por las repúblicas andinas o de los recursos naturales explotables, a pesar de que hacia finales del siglo XVIII ya existía allí actividad minera, comercial y agrícola, como que si a pesar de la generalidad planteada en la imaginabilidad territorial que reflejaba, ésta resultaba suficientemente

mitos de la ocupación del desierto y del descubrimiento del salitre a la urbanización de la pampa, 1870-1920"; González, Sergio y Artaza, Pablo. 2013. "El concepto de cantón salitrero y su funcionalidad social, territorial y administrativa: los casos de Zapiga, Lagunas y El Toco"; González, Sergio y Godoy, Milton. 2013. "Norte Grande y Norte Chico: construcción social de un imaginario compartido, 1860-1930". Todos ellos en González, Sergio (comp.), La Sociedad del Salitre. Protagonistas, migrantes, cultura urbana y espacios públicos, 1870-1940, Santiago, Ril Editores. Ver también González, Sergio. 2009. “El Norte Grande de Chile: la definición histórica de sus límites, zonas de líneas de fronteras, y la importancia de las ciudades como geosímbolos fronterizos", pp. 1-25.

37 Para este contexto, sería correcto también trabajar con el concepto "cosmografía", utilizado ampliamente por los cartógrafos medievales y modernos para referirse a la producción de mapas, sobre todo aquellos que buscaban representar todo el territorio conocido o explorado por la humanidad, incluyendo el espacio (cielo) observable y estudiado por la astronomía.

${ }^{38}$ Aguilar, José. 1967. Historia de la cartografía: la tierra de papel. Buenos Aires, Editorial Codex; Molinari, Diego. 1941. El nacimiento del nuevo mundo: 1492-1534, historia y cartografía, Buenos Aires, Editorial Kapeluz; Levinas, Marcelo y Vidal, Silvina. 2016. "La cosmografía de Waldseemüller, la conceptualización de 'América' y su relación con el copernicanismo", en Scientiae Studia, Vol. 14, № 2, Sao Paulo, pp. 281-331.

${ }^{39}$ Rosenblitt, Jaime y Sanhueza, Ma Carolina. 2010. Cartografía histórica de Chile; Dym, Jordana. 2010. “Presentación: Mapeando patrias chicas y patrias grandes: cartografía e historia iberoamericana, siglos XVIII-XX", en Araucaria Revista Iberoamericana de Filosofía, Política y Humanidades, № 24, Sevilla, pp. 99-109; Hidalgo, Jorge. 2009. “Civilización y fomento: la 'descripción de Tarapacá' de Antonio O’Brien, 1765", en Chungara, Vol. 41, № 1, Arica, pp. 5-44. 
funcional a los requerimientos y exigencias que la carga de valor prevaleciente en ellos ofrecía a una forma de incorporación poco intensiva ${ }^{40}$.

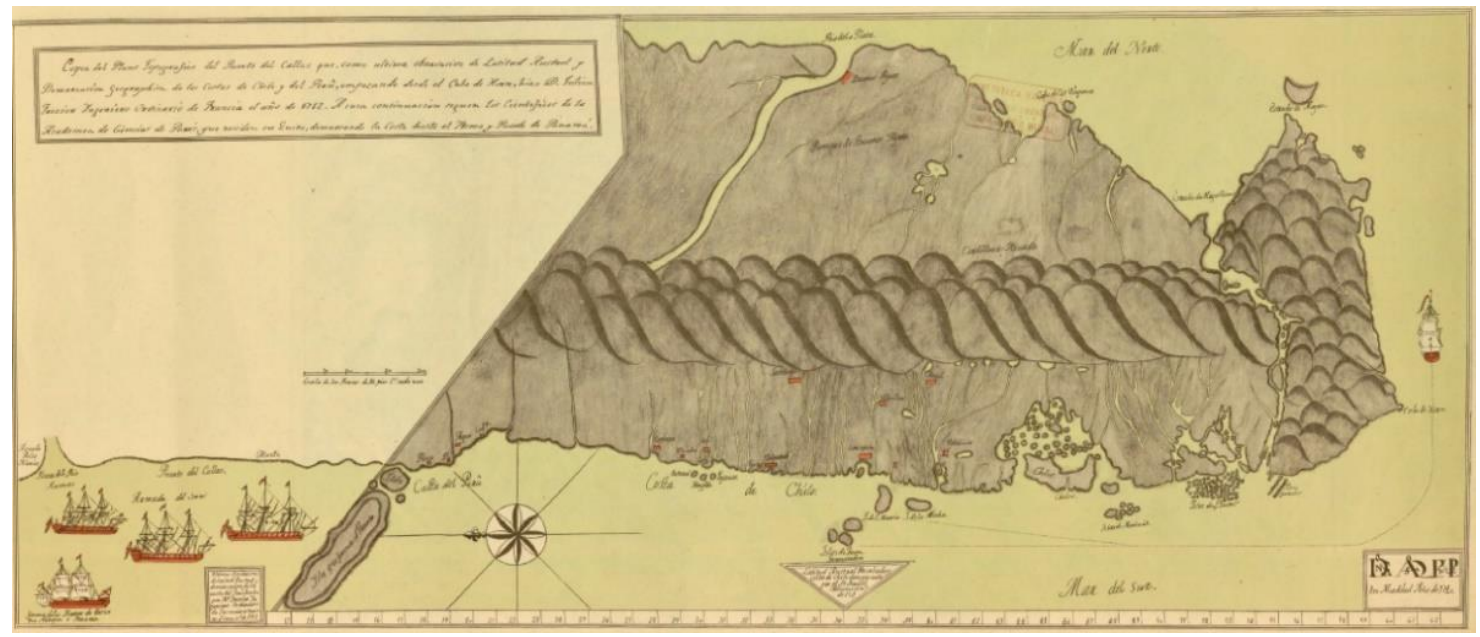

Figura 1. Copia del plano topográfico del Puerto del Callao, Amadée Frezier, 1712.

En él se observa el desierto de Atacama entre Arica a Copiapó.

En el siglo XIX y en el caso peruano, en 1812 los cartógrafos británicos Aaron Arrowsmith y Samuel Lewis cartografiaron e incluyeron en su Atlas el territorio del hasta entonces Virreinato del Perú, donde aparecen Arica, Pisagua, Iquique y el río Loa como puntos fuertes de referencia en lo que se conocerá posteriormente como Tarapacá ${ }^{41}$. En este caso, el interés por cartografiar el área fue de carácter intelectual, pero evidentemente también hubo detrás intereses imperiales y económicos, sobre todo debido a la expansión del imperio británico y sus pretensiones de influir en el continente americano durante y después de los procesos independentistas. Mismo caso se registra con John Pinkerton quien representó en 1815 y 1818 parte de Sudamérica (provincias del Río de la Plata, parte Centro-Norte de Chile, Bolivia y Sur del Perú) en dos mapas distintos, donde el descampado de Atacama aparece claramente como provincia boliviana, mientras que Tarapacá es el territorio más al Sur del Perú, perteneciendo en ese entonces al Departamento de Arequipa.

Posteriormente, entre las décadas de 1820 y 1850 destacaron otros trabajos cartográficos en que se incluyó el territorio de Tarapacá como el más austral de la joven república peruana, entre ellos el de Lucas Fielding (1823), Pierre Lapie (1833), Agustín Codazzi (1840) o John Tallis

\footnotetext{
${ }^{40}$ Vicuña Mackenna, Benjamín. 1882. El libro de la plata, Santiago, Imprenta Cervantes; Pinto, Julio. 1997. Episodios de historia minera: estudios de historia social y económica de la minería chilena, siglos XVIII-XIX, Santiago, Universidad de Santiago; Contreras, Carlos. 2013. "Transferencia de tecnologías e Imperio. El caso de la minería andina en el siglo XVIII", en Diálogo Andino, № 33, Arica, pp. 29-42.

${ }^{41}$ Arrowsmith, Aaron \& Lewis, Samuel. 1812. Viceroyalty of Perú. En A new and elegant general atlas, comprising all the new discoveries, to the present time, Boston, Thomas and Andrews.
} 
(1850), entre muchos otros, los que sirvieron política y económicamente al Perú para asegurar su soberanía sobre ese territorio y definir sus límites con Chile y Bolivia. En todos estos, el factor más importante era el de reflejar la extensión hacia el sur de la república del Perú, asegurando su soberanía.

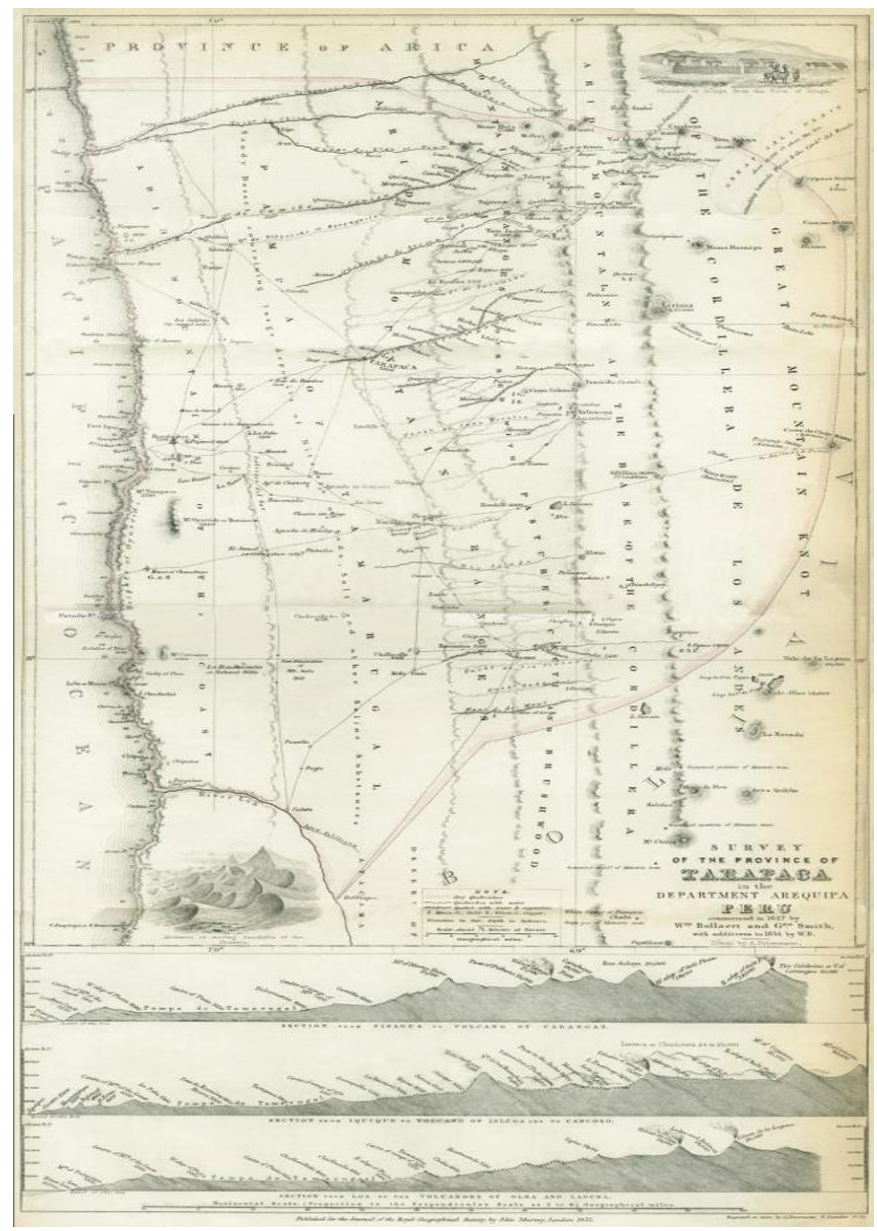

Figura 2. William Bollaert y Jorge Smith, Survey of the province of Tarapacá in the Department Arequipa. Perú, 1851.

Todos estos últimos trabajos parecieran anticipar el rol y funcionalidad que vendría a desarrollar el más importante de destacar en este período, consistente en el trabajo de William Bollaert y George Smith, quienes fueron contratados por el Estado peruano para producir conocimiento geográfico y cartográfico de Tarapacá y con la finalidad de reconocer las faenas productivas desarrolladas en ese espacio y territorio. Como ya ha sido destacando por quienes lo han abordado, ese encargo tuvo como resultado un estudio y un mapa publicado en 1850, que representa a Tarapacá como uno de los territorios más ricos mineralógicamente hablando 
del Perú, sobre todo los yacimientos de Huantajaya, Santa Rosa y los terrenos salitreros de la pampa, además de entregar datos sociales y antropológicos de su población ${ }^{42}$.

Posteriormente, en 1871 Daniel Barrera dio un nuevo salto técnico en el área cartográfica, produciendo un Mapa del Perú mucho más detallado, en el que puso énfasis en los yacimientos minerales, los flujos entre los puertos de Tocopilla, Iquique y Arica, algunas localidades de la pampa y los caminos de esta que conectaba a Tarapacá con el resto del Perú.

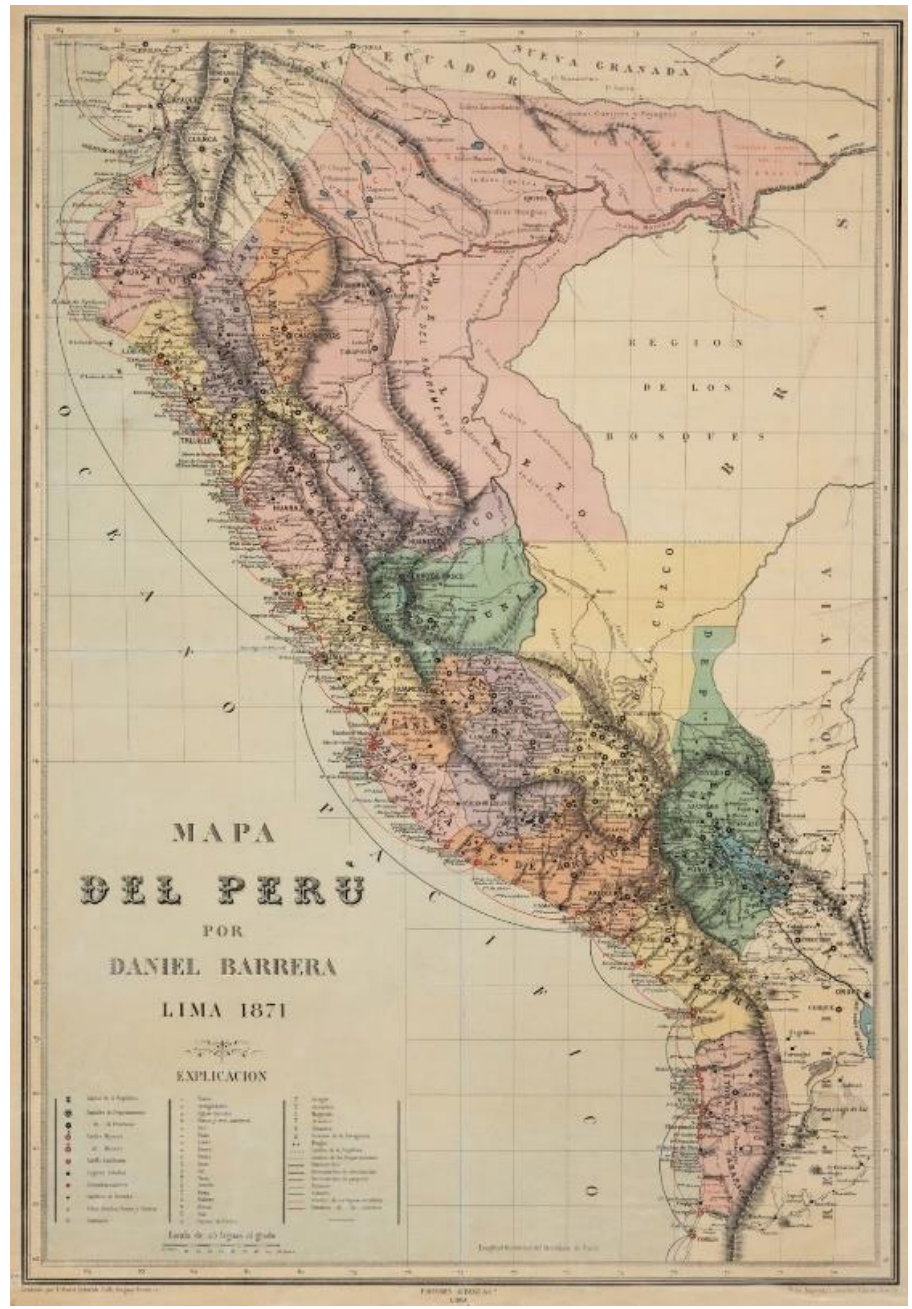

Figura 3. Mapa del Perú, Daniel Barrera, 1871.

42 Bollaert, William. 1975. "Descripción de la provincia de Tarapacá", en Norte Grande, Vol. 1, №s 3-4, Santiago, pp. 461-479; Crozier, Ronald. 1996. "William Bollaert, explorador y publicista", en Boletín de la Academia Chilena de la Historia, 106, Santiago, pp. 205-250; Castro, Luis; Figueroa, Carolina, Guerrero, Pablo y Silva, Benjamín. 2017. "William Bollaert y sus descripciones geográficas, cartográficas y antropológicas sobre la provincia de Tarapacá en la etapa inicial de la formación republicana del Perú, 1827-1854", en HISTORElo Revista de Historia Regional y Local, Vol. 9, № 18, Medellín, pp. 123-163. 
Lo mismo pasó años después con Mateo Paz Soldán (1812-1857) quien en su última etapa de trabajo generó dos importantes y muy conocidos estudios geográficos, los que serían de relevancia en las disputas limítrofes entre Bolivia, Perú y Chile. En su Atlas Geográfico de la República del Perú y Geografía del Perú -ambos textos publicados póstumamente por su hermano Mariano ${ }^{43}$-, desarrolló importantes descripciones y representaciones del desierto de Atacama y de Tarapacá, provincia que para entonces dependía del Departamento de Moquegua, haciendo énfasis en sus riquezas naturales, entre ellas el salitre, que era exportado por el puerto de lquique, superando para el año 1859 el millón y medio de quintales métricos ${ }^{44}$.

Todo lo anterior no solo refleja una constatación explícitamente geoeconomicista de la atracción creciente que comenzaban a despertar las riquezas minerales de Tarapacá, sino que también una geolocalización de los sitios más importantes en esa parte del desierto, contribuyendo al proceso de construcción del Estado Nación peruano y su hegemonía y soberanía territorial. La existencia de minas de plata, bórax y mantos salitreros nos permiten constatar y reforzar la existencia de grupos humanos que trabajaron en esas faenas, la tecnología utilizada y los capitales invertidos, además de graficar en algunas partes la circulación transfronteriza en ese espacio. En todos estos mapas aparece además el río Loa como límite entre el Tarapacá de Perú y la Antofagasta de Bolivia ${ }^{45}$.

Para el caso chileno, el principal recopilador de la cartografía colonial chilena y americana durante el siglo XIX fue el anteriormente nombrado José Toribio Medina ${ }^{46}$, quien en su plan de trabajo para desarrollar la Biblioteca Americana, reunió una infinidad de planos, cartas y mapas en varios de sus textos, naciendo así la Geografía antigua de Chile: nomenclatura de nombres geográficos indígenas de Chile (1880), la Colección de mapas y planos: Catálogo de la colección de mapas, planos y vistas relativo a Chile (1889) y finalmente su Ensayo acerca de una mapoteca chilena (1889).

La importancia de estos dos últimos textos, que hoy son posibles de definir como las primeras mapotecas de Chile por su detallada catalogación y ordenamiento cronológico y alfabético, es que rescató no solo material colonial, sino que también las producciones hechas por las comisiones científicas que recorrieron el desierto de Atacama y otras partes del país ${ }^{47}$,

\footnotetext{
${ }^{43}$ Paz Soldán, Mariano. 1878. Verdaderos límites entre Perú y Bolivia, Lima, Imprenta Liberal, 74 páginas.

44 Paz, Mariano. 1862. Geografía del Perú, Lima, Imprenta Liberal, 746 páginas; González, Sergio y Artaza, Pablo. 2013. "El concepto de cantón salitrero y su funcionalidad social, territorial y administrativa: los casos de Zapiga, Lagunas y El Toco", pp. 325-363.

45 González, Sergio. 2009. "El Norte Grande de Chile: la definición histórica de sus límites, zonas de líneas de fronteras, y la importancia de las ciudades como geosímbolos fronterizos", pp. 1-25.

${ }^{46}$ Bromsen, Maury. 1969. José Toribio Medina, humanista de América, Santiago, Andrés Bello.

47 Sagredo, Rafael. 2018. J. T. Medina y su biblioteca americana en el siglo XXI: prácticas de un erudito, Santiago, DIBAM; Medina, José Toribio. 1889. Ensayo acerca de una mapoteca chilena ó sea de una colección de los títulos de los mapas, planos y vistas relativos á Chile arreglados cronológicamente: con una introducción histórica acerca de la
} 
volviendo explícito el interés creciente que jugaba sobre las elites chilenas la expansión territorial que permitiría el control de las riquezas allí depositadas. Por ello, en paralelo a la consolidación del Estado Nación chileno, los sucesivos gobiernos se vieron en la necesidad de visualizar y luego representar el territorio nacional para conocer su ubicación y extensión geográfica, definir sus límites y, por supuesto, para el reconocimiento de sus riquezas naturales. De esa forma, se contrató a profesionales en las diferentes áreas de las ciencias físicas y naturales, y entre ellos, a naturalistas, geógrafos y mineralogistas que desarrollaron exploraciones en el entonces descampado de Atacama, partiendo desde la provincia de Aconcagua hacia el Norte. Claudio Gay (1830), Ignacio Domeyko (1838), Amadeo Pissis (1848) y Rodulfo Philippi (1856) son nombres recurrentes dentro de los estudios históricos al respecto. Todos estos intelectuales, en la medida de sus posibilidades y recursos, recorrieron el descampado de Atacama, escribieron estudios geográficos, mineralógicos y dibujaron cartas o mapas de éste, intentando desarrollar una representación científica de aquello que observaron, aunque generando igualmente un vaciamiento cartográfico, puesto que entre sus objetivos ocupaba un lugar destacado el servir a los intereses económicos del Estado de Chile y de los empresarios tanto nacionales como extranjeros.

En el mapa mineralógico producido por Pissis en 1877, por ejemplo, se detallan preferentemente los elementos fundamentales para consolidar una apropiación de este espacio bajo los parámetros correspondientes a un territorio convenientemente capitalizado, como los puertos, las líneas de ferrocarril, caminos y ríos, algunas villas y las explotaciones salitreras entre Antofagasta y Cachinal, las minas de plata y cobre, entre otros aspectos con elevado valor de uso y de cambio. La intencionalidad detrás de este mapa era, por un lado, manifestar la existencia de riquezas minerales en explotación y/o posibles de explotar y, por otro, demostrar que la noción de descampado era errónea, puesto que quienes pretendiesen internarse en él, no solo encontrarían caminos por donde circular, sino que además transporte y conectividad, aguadas y ríos para el sustento diario, y pueblos donde resguardarse y abastecerse de mercaderías. Al mismo tiempo, definía el límite entre Chile y Bolivia solo algunos kilómetros al sur de Antofagasta, con lo que aseguró al Estado de Chile la posibilidad de reivindicar esos territorios. A través de ellos, ya se observa una intencionalidad de conocimiento moderno sobre las potencialidades ofrecidas por el territorio, y por medio de este mismo acto, una pretensión de poder.

Los mapas y cartas de estos científicos y naturalistas fueron posteriormente la base del conocimiento empírico para otros intelectuales que se dieron la tarea de representar los territorios ya señalados. Entre los que la continuaron se encuentra Alejandro Bertrand en un

geografía y cartografía del pais, Santiago, Ercilla; Instituto Geográfico Militar. 1952. Cartografía hispano colonial de Chile. Il atlas: homenaje del Ejército de Chile a José T. Medina, Santiago, Instituto Geográfico Militar. 
lugar destacado, uno de los más importantes y prolíficos intelectuales de la segunda mitad del siglo XIX. Ingeniero y Geógrafo, Bertrand dedicó parte importante de sus estudios a lo que hoy conocemos como el Norte Grande chileno. Previo a la Guerra con Perú y Bolivia, en 1877 publicó su Carta de Chile, un mapa modificado que se basó en los trabajos previos de Robert Fitz-Roy y Amadeo Pissis, siendo dirigido por Pedro Lucio Cuadra, quien había acompañado a Pissis en sus expediciones al desierto ${ }^{48}$.

Su período más fecundo en materia cartográfica fue en 1879, año en que produjo dos mapas titulados Carta de los desiertos de Tarapacá y Atacama y otro centrado en la ocupación militar de Chile, que denominó Territorio ocupado en Tarapacá por el ejército chileno. Posteriormente publicó en 1885 el mapa Chile: Provincias Septentrionales formadas en los territorios anexados $i$ ocupados temporalmente, en que aparecen ya definidos como provincias chilenas Tacna, Tarapacá y Antofagasta. Una de las "cartas de los desiertos" fue adjuntada por Bertrand en su estudio de 1879 titulado Noticias del departamento litoral de Tarapacá y sus recursos, obra producida bajo el auspicio de la Oficina Hidrográfica de Chile y su Sección de Cartas y Planos ${ }^{49}$. Al respecto, es posible afirmar que este mapa es una ficción o abstracción territorial y del espacio social en cuestión, ya que para su confección utilizó la representación cartográfica y geográfica de una diversidad de autores con intereses y períodos de tiempo muy distintos y entre ellos los trabajos de los hermanos Paz Soldán.

Con respecto a la división del Departamento de Tarapacá, Bertrand señaló varios distritos y su número de población hacia el año 1876: Camiña (1.297), Chiapa (1.126), Iquique (15.575), Pica (8.236), Pisagua (1.079), Tarapacá (3.932), Mamiña (1.042). A lo anterior agregó descripciones mineralógicas y geográficas, dividiendo el territorio en zonas, destacando también otras divisiones administrativas del territorio. De los poblados salitreros, refiriéndose a estos ya no como distritos, sino que, como cantones, escribió:

"Las salitreras se dividen en tres grandes secciones: del Norte, del Centro y del Sur; y cada una de ellas en cantones, como Sal de Obispo, Negreiros, La Noria, La Peña, etc. Se calcula que solo la parte del terreno explotado para sacar salitre ocupa como 50 leguas cuadradas, y dará cuando menos 63 millones de toneladas de este producto." ${ }^{50}$

El trabajo cartográfico de Alejandro Bertrand fue acompañado posteriormente -cuando ya ejercía como delegado fiscal de salitreras- por otros dos importantes estudios sobre la provincia de Tarapacá, uno geográfico y otro económico: Departamento de Tarapacá: aspecto

\footnotetext{
48 González, Sergio. 2013. "Alejandro Bertrand Huillard (1854-1942)", en Bertrand, Alejandro. 2013. Memoria acerca de la condición actual de la propiedad salitrera en Chile, Santiago, Pontificia Universidad Católica de Chile, Cámara Chilena de la Construcción, DIBAM, pp. IX-LVIII.

${ }^{49}$ Bertrand, Alejandro. 1879. Noticias del Departamento Litoral de Tarapacá y sus recursos, Santiago, Imprenta Nacional.

50 Ídem, p. 6.
} 
jeneral del terreno, su clima i sus producciones (1879) y Memoria acerca de la condición actual de la propiedad salitrera en Chile (1892).

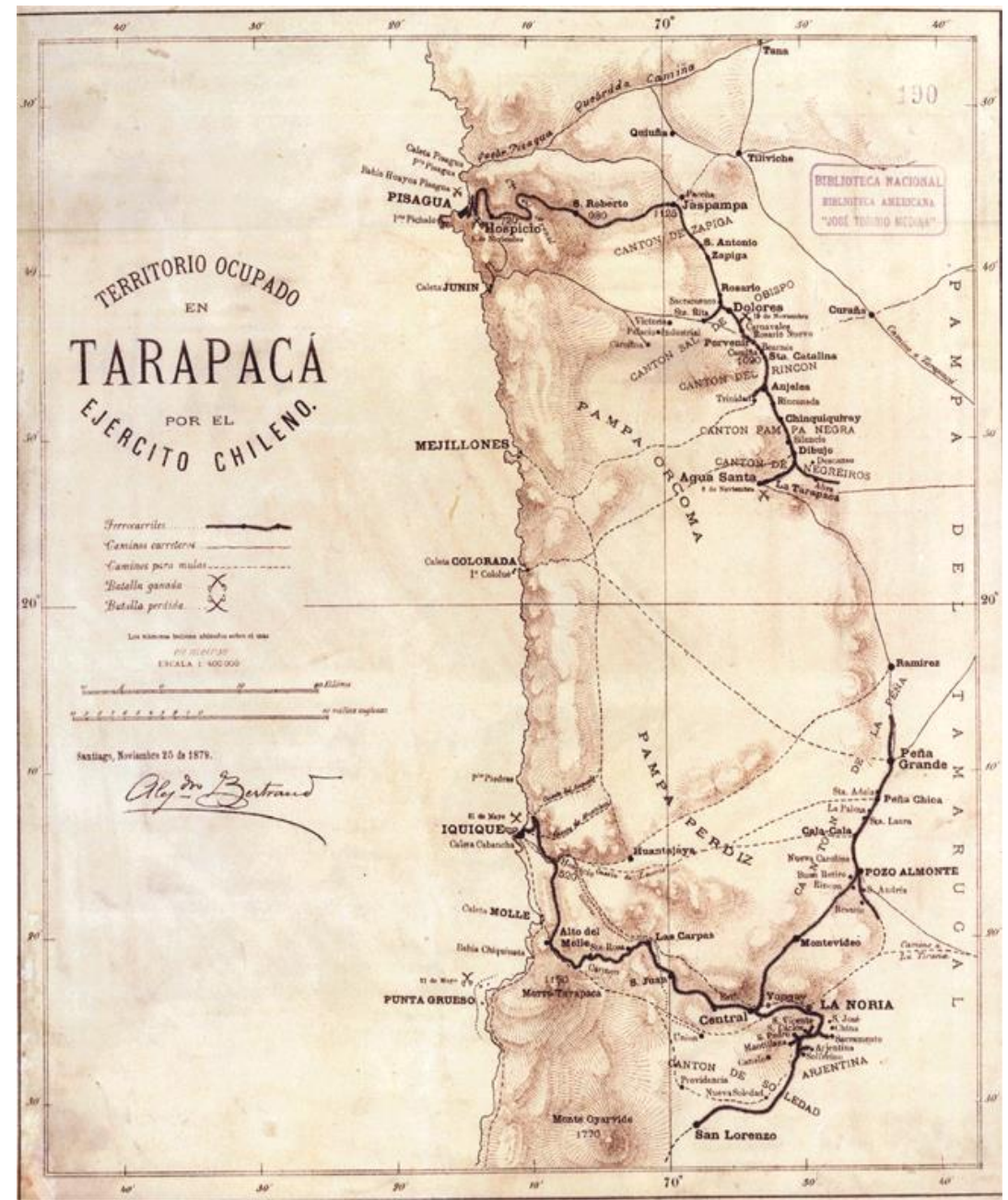

Figura 4. Alejandro Bertrand, "Territorio ocupado en Tarapacá por el Ejército Chileno", 1879.

Ya los trabajos previos a la Guerra del Pacífico de Bertrand permiten cerrar un ciclo en que el territorio del desierto de Atacama y Tarapacá pasan de "descampado" estéril a ser espacios poblados y llenos de riquezas, cuestión que también repercutió en la forma en que se produjeron las cartas, mapas, planos y todo producto técnico-intelectual derivado del estudio del territorio. Esto demuestra el desarrollo de un perfeccionamiento del trabajo cartográfico que se siguió especializando y complejizando después con la consolidación del dominio del Estado de Chile y los empresarios asociados sobre los nuevos territorios anexados. A la vez que anticipó la forma en que el Estado nación chileno, y por su intermediación, el polo dominante 
de la economía mundial, visualizaron la transformación que operaría sobre este territorio, pues el componente privilegiado en las representaciones cartográficas del período priorizaba tanto los componentes técnicos como la materialidad existente que volvía propicio un posterior salto exponencial en la expansión productiva de la industria salitrera.

\section{Cartografía de Tarapacá durante el ciclo salitrero chileno (1880-1930)}

Tras la Guerra del Pacífico y la anexión de los territorios de Tacna, Tarapacá y Antofagasta bajo la hegemonía y soberanía del Estado de Chile, fueron diversas las cartas y mapas que se produjeron tras el estudio de ambas regiones que pasaron a ser el nuevo Norte Grande chileno, relegando a los territorios al sur de Copiapó a ser reconocidos como "Norte Chico", a pesar de haber sido el "Norte histórico" del país ${ }^{51}$.

El interés por representar estas regiones estuvo basado, al igual que lo había hecho anteriormente el Perú, en un reconocimiento de los nuevos territorios y espacios, sus localidades y recursos, además de crear una imagen unificada, de servir de base para el despliegue de un discurso nacionalista y generar un simbolismo económico en torno a su anexión, aunque con claridad, la razón principal para realizar esa tarea fue la de facilitar la explotación minera en general y específicamente del salitre ${ }^{52}$.

De este fluctuante periodo de crecimiento y crisis económica de carácter cíclico, nos interesa revisar algunos mapas y cartas que representaron de manera bastante acabada los fenómenos económicos y la transformación territorial que se llevó a cabo en Tarapacá entre 1880 y 1930, incluyendo algunos mapas relacionados netamente con los ferrocarriles de la zona norte del país.

En 1892 por ejemplo, Ferrocarriles del Estado público su Mapa de los ferrocarriles de Chile, apareciendo en su primera parte el mapa de los ferrocarriles de Tarapacá, donde -como era de esperarse- el punto central de la representación fueron las líneas públicas y privadas, y la distinción entre las en explotación y las proyectadas, apareciendo solo algunas localidades del territorio -incluyendo el puerto de lquique- y algunos elementos geográficos como ríos y quebradas. En el caso del ferrocarril salitrero, aparecen las líneas en explotación que partían en los puertos de Pisagua, Caleta Buena e Iquique, mientras que destacaba los que se encontraba

\footnotetext{
51 González, Sergio y Godoy, Milton. 2013. "Norte Grande y Norte Chico: construcción social de un imaginario compartido, 1860-1930", pp. 195-213.

${ }^{52}$ Arellano, Nelson. 2017. "El desierto de Atacama como laboratorio: experimentos y tecnologías de la energía solar", en Revista Mundo, Vol. 22, № 44, San Cristóbal, pp. 81-89; Galaz-Mandakovic, Damir. 2019. Movimientos, tensiones y luces. Historias tocopillanas, Tocopilla, Ediciones Bahía Algodonales, 306 páginas; Artaza, Pablo. 2018. "La producción social del espacio salitrero tarapaqueño durante el ciclo de expansión: entre la necesidad patronal de control social y la resistencia de la sociedad pampina", en Tiempo Histórico, № 17, Santiago, pp. 47-84; Artaza, Pablo. 2018. "Los cantones salitreros como espacio de tránsito y circulación. Tarapacá durante el ciclo de expansión del salitre", en Revista Chilena de Antropología, № 37, Santiago, pp. 164-182.
} 
en proyecto, como la línea hacia el sur que posteriormente conectó a los establecimientos salitreros de Lagunas con el resto de los cantones y oficinas salitreras y que tendría a Patillos como caleta de embarque. Tratándose de una explotación mineral que basaba sus patrones de acumulación en la ampliación del volumen de explotación y exportación a mercados muy lejanos, el transporte desde las zonas de producción situadas preferentemente en el interior del territorio hasta los puertos y caletas de embarque -pensado a nivel de su existencia disponible, su ampliación y la disminución en los costos asociados que ello traería aparejadoresultaba fundamental para los mecanismos del poder interesados en volcarse sobre el territorio para transformarlo en un espacio socialmente utilizado.

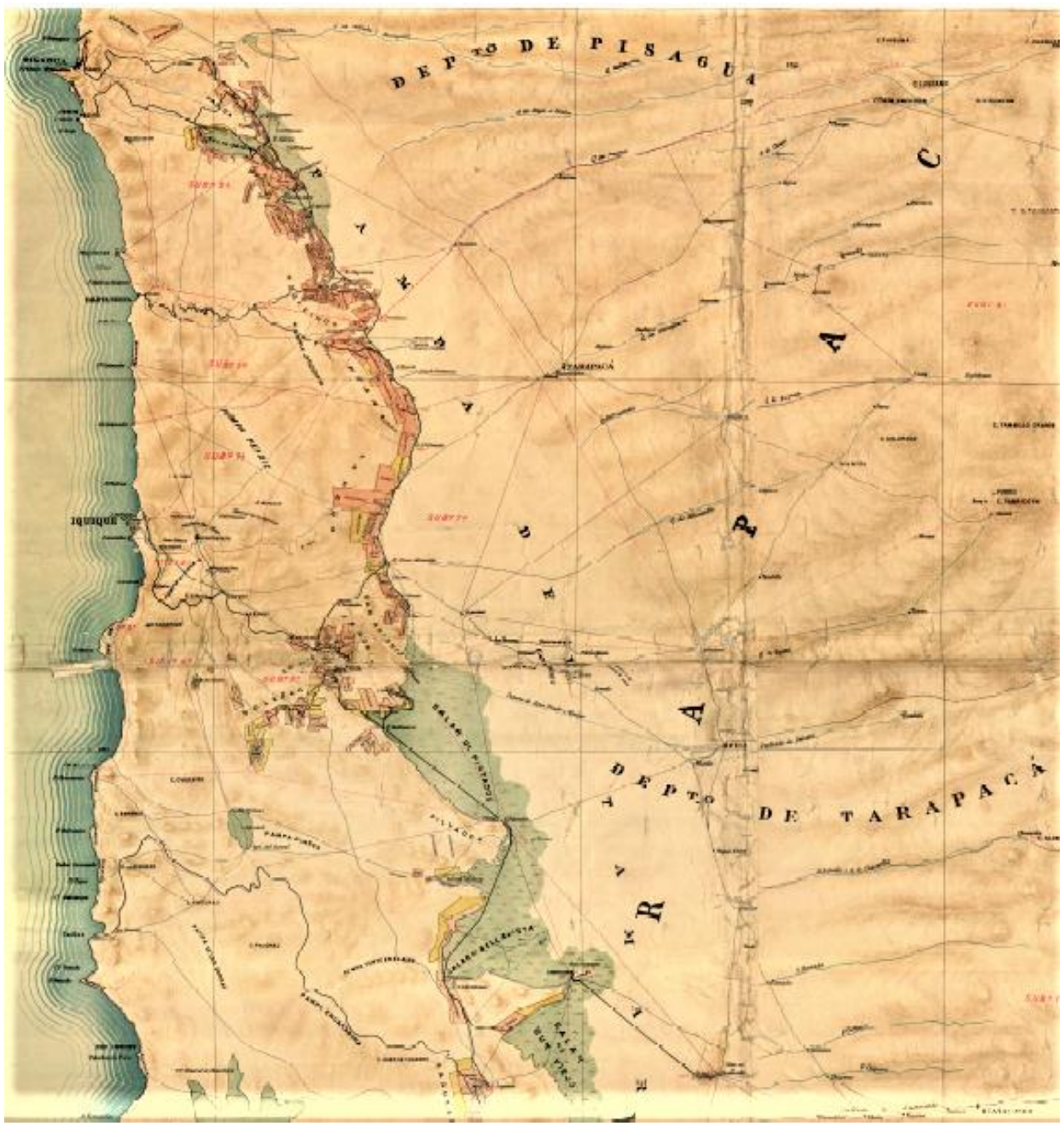

Figura 5. Territorio salitrero de Tarapacá, fragmento del Plano de la región salitrera desde Arica a Tocopilla (1896) 
En esta misma línea de interpretación, no resulta extraño que uno de los mapas más detallados hacia fines del siglo XIX fue el producido en 1896 por la Delegación Fiscal de Salitreras, el que fue confeccionado para representar especialmente el crecimiento de la industria del salitre en Tarapacá y parte de Antofagasta, titulado Plano de la región salitrera desde Arica a Tocopilla. Este fue uno de los primeros en graficar de manera completa la nueva división administrativa de la Provincia de Tarapacá, primero en departamentos (Arica, Pisagua y Tarapacá), luego en ocho subdelegaciones, aunque mantuvo la tradicional denominación de las "pampas" como Pampa Orcoma, Pampa Perdiz, Pampa Blanca o Pampa Tente en el Aire por nombrar algunas de las ubicadas en la "zona de producción salitrera" y que se encuentran contenidas en la gran Pampa del Tamarugal que se extiende hasta el río Loa.

Al interior de esas "pampas" se encontraban los igualmente tradicionales cantones salitreros que agruparon a las oficinas, junto a los terrenos calicheros, pueblos y estaciones de ferrocarriles. Otros detalles significativos de esta representación cartográfica son los salares cercanos a cada pampa calichera, las quebradas que cruzan de cordillera a mar el territorio de Tarapacá, la articulación de los ferrocarriles desde los puertos y caletas topando hacia el interior con el tramo norte del ferrocarril longitudinal y dividiéndose en las numerosas líneas del ferrocarril salitrero y sus ramales privados; vías de comunicación que fueron utilizados también como rutas comerciales, yacimientos mineros contiguos a las oficinas salitreras o cercanos a la costa, entre muchos otros elementos.

La mayor parte de lo expuesto anteriormente se articula hacia un gran centro costero, el puerto de lquique, que aparece representado con sus respectivas cuadrículas, lugar desde el cual salió el salitre al mundo y por el cual entraron infinidad de productos de consumo nacionales y extranjeros- para la sociedad salitrera, insumos para la industria, flujo de capitales, población migrante en búsqueda de trabajo, etcétera.

Por su parte, las oficinas salitreras aparecen divididas por colores, diferenciando así entre pertenencias fiscales y pertenencias privadas, señalándose oficinas que posteriormente no fueron referenciadas en otros mapas como Jazpampa Bajo, además de dibujar las cañerías o bocatomas que usaron el agua de las quebradas, de los pozos naturales y napas subterráneas del interior de Tarapacá para surtir el amplio consumo de la industria y las personas.

Por supuesto, como todo mapa de este tipo, deja a la imaginación del observador el ubicar las instalaciones industriales y máquinas, el lugar de las casas de administración, pulperías o cuarto para obreros, la diferenciación entre pueblos-estación y localidades tradicionales, lugares de abastecimiento, cocinerías, chincheles o prostíbulos. Su finalidad no es exponer el contexto y las relaciones sociales de producción, sino que más bien realizar un catastro cartográfico del territorio y como la industria salitrera lo ha intervenido tras el término de la guerra y la implementación de la política fiscal de carácter liberal por parte del Estado de Chile. 
A través de esta representación cartográfica, la agencia responsable de su elaboración daba cuenta de la velocidad con que se había alcanzado la madurez de la incorporación de estos nuevos territorios, los que no solo habían registrado el cambio de adscripción subordinada a otro Estado, sino que con similar rapidez, ya había sido definido y delimitado por medio de una nueva división administrativa, la que permitía controlar el paso de este componente biofísico recientemente adquirido a constituirse en un espacio capitalizado, sobre el cual se volcaba esta nueva conjunción de intereses públicos y privados, nacionales y sobre todo extranjeros, que de esta forma, permitiría la más expedita interconexión entre los recursos disponibles en esta apartada provincia -dentro del cual el salitre ocupaba un lugar absolutamente central-con las áreas centrales de la economía global.

En 1910, la Delegación Fiscal de Salitreras actualizó su producción cartográfica, esta vez publicando el trabajo titulado Carta de la región salitrera comprendida entre los paralelos $19^{\circ}$ y $27^{\circ} 30^{\prime}$ Lat. Sur. Las diferencias con el mapa anteriormente detallado inician con la extensión del territorio que representó, partiendo en el norte desde la quebrada y pampa de Camarones, pasando por las provincias de Tarapacá y Antofagasta, hasta llegar a Copiapó por el sur. Es decir, esta nueva carta incluyó a todo el territorio que actualmente conocemos como Norte Grande e impuso esa visión simbólica y fragmentación territorial específica de esas regiones.

Se mantuvo gran parte de la estructura anterior, manteniendo los yacimientos mineros metálicos y no metálicos desde la cordillera hacia la costa e incluyendo una tabla en la que se referenció la nómina completa de las oficinas salitreras existentes hasta ese año en Tarapacá, Tocopilla, Antofagasta y Taltal.

En el caso del tramo correspondiente a la Provincia de Tarapacá aparecen mucho más completos los ferrocarriles, además de agregarse los caminos carreteros y troperos que conducían hacia los pueblos del interior y hacia la zona limítrofe con Bolivia. En el caso de las oficinas y los mantos calicheros ya no se diferenció entre públicos y privados, identificando el espacio de cada uno con un número que coincide con los nombres de la nómina adjunta.

A diferencia de la representación anterior, esta ya da cuenta de la transformación operada sobre el territorio por medio de una más amplia y completa imaginabilidad territorial del espacio socialmente utilizado para la explotación salitrera. A partir de los altos rendimientos obtenidos por la acumulación capitalista gracias a la expansión de la industria salitrera, el espacio apropiado para su explotación se amplía hacia el sur, anticipando incluso la transferencia que algunos años más adelante, se suscitaría entre una explotación concentrada en Tarapacá hacia la provincia de Antofagasta, en la que se experimentarán mayores niveles de modernización de la explotación de las riquezas salitreras. De igual forma, desde su propia denominación, esta Carta de la región salitrera, da cuenta de una producción social del espacio que prioriza la riqueza contenida en el territorio para integrar la zona ampliada del espacio salitrero. 


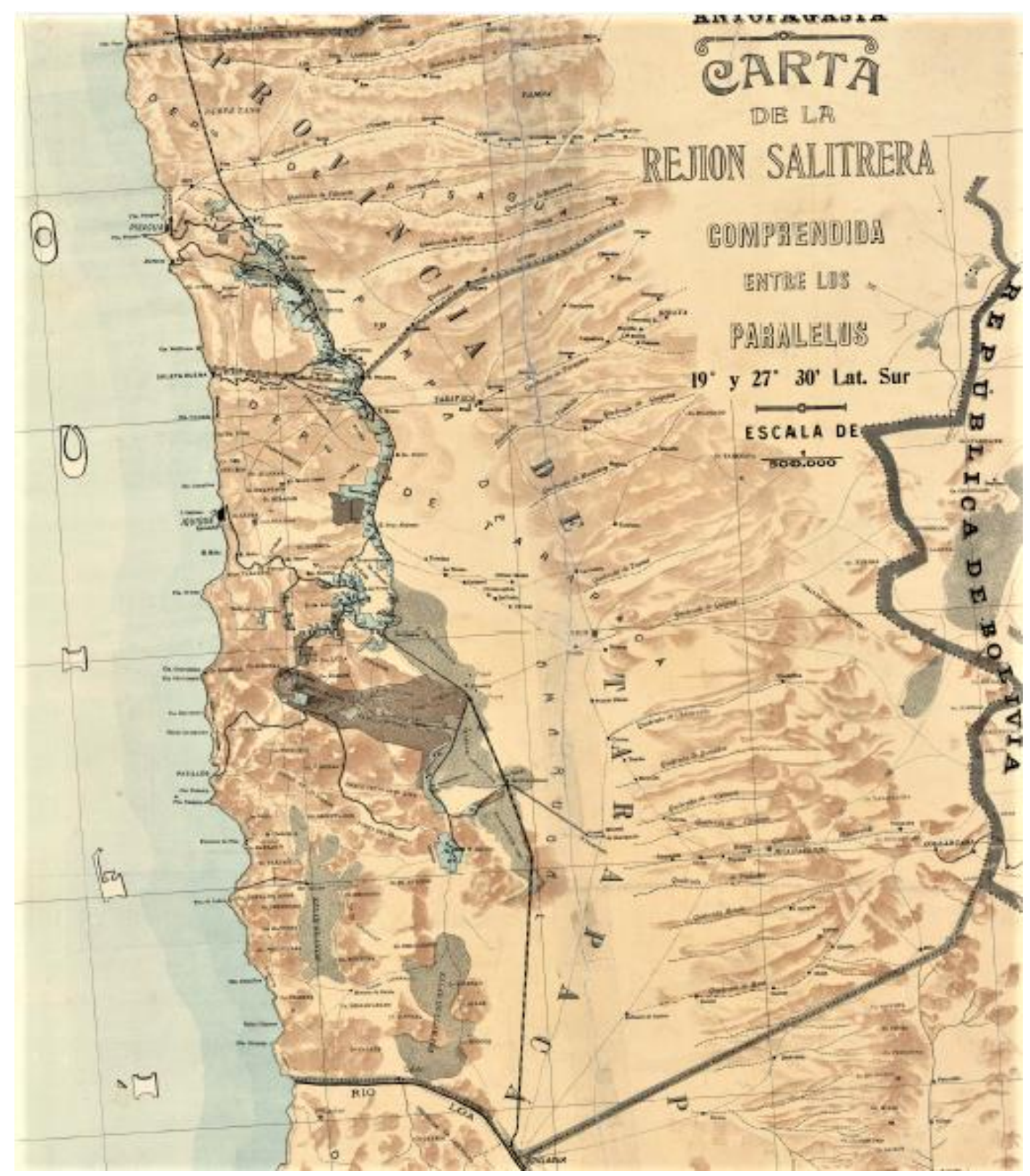

Figura 6. Territorio salitrero de Tarapacá, fragmento de la "Carta de la región salitrera comprendida entre los paralelos $19^{\circ}$ y $27^{\circ} 30^{\prime}$ Lat. Sur" (1910)

Muy parecido y a la misma altura técnica de representación y detalle, fue el mapa de Chile solicitado por el Presidente Pedro Montt en 1910 y confeccionado por Luis Risopatrón como director de la Oficina de Mensura de Tierras. En este mapa, aunque no es específicamente 
salitrero ya que incluyó también al resto de provincias del país, se detalló claramente los ferrocarriles salitreros y de la zona norte en general y se agregó el nombre de muchas localidades y oficinas salitreras, pero no se diferenció entre unas y otras. Se mantuvo además detalles geográficos como las quebradas, pampas, ríos, salares y la frontera cordillerana.

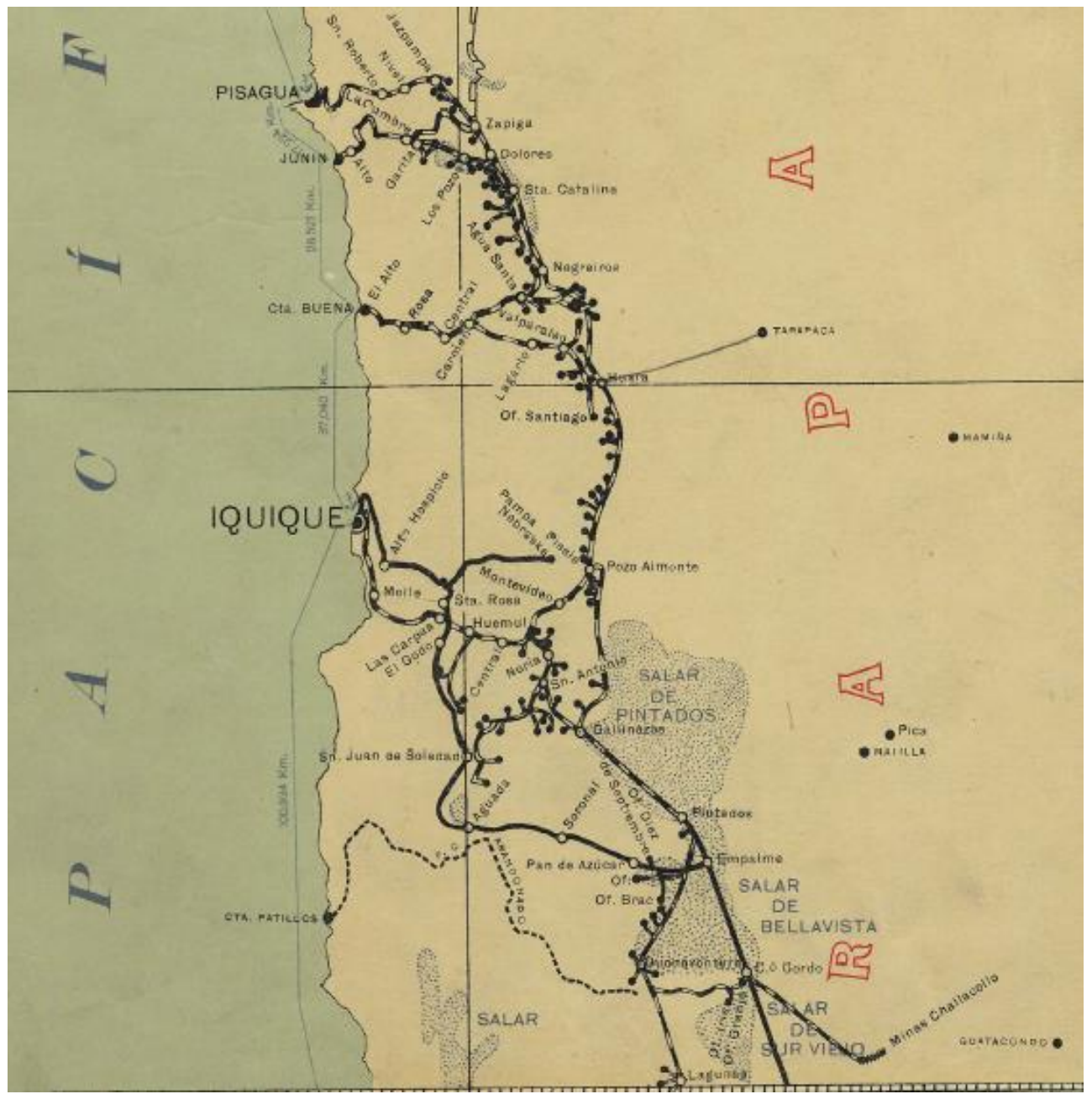

Figura 7. Red de ferrocarriles de Tarapacá representados en "Ferrocarriles de Chile" de la Dirección de Obras Públicas, Departamento de Ferrocarriles, 1929.

Un mapa menos detallado, pero a la vez más específico en relación con el sentido que guiaba la representación, fue el de José Fuenzalida denominado Carta minera de la zona de atracción del ferrocarril longitudinal entre Calera y Pintados, centrado en destacar solo las líneas férreas desde Iquique por el Norte hasta Papudo en la Provincia de Aconcagua por el Sur. En el caso de la zona salitrera de Tarapacá, Fuenzalida incluyó solo algunas de las más importantes oficinas 
salitreras entre Iquique y Lagunas, siendo estas también algunas de las estaciones del ferrocarril salitrero y del ferrocarril longitudinal.

Esta misma fórmula fue utilizada con posterioridad por la Inspección Superior de Ferrocarriles en 1926 y el Departamento de Ferrocarriles del Ministerio de Fomento en 1929, poniendo énfasis solo en los tramos terminados y explotados de los ferrocarriles salitreros y longitudinal, vaciando del resto del contenido espacial y territorial a esas representaciones cartográficas. Claramente, esto se debió a la intencionalidad de esas instituciones de catastrar específicamente los ferrocarriles y sus estaciones, dejando fuera incluso elementos industriales o económicos en general. La prioridad, era ahora dar cuenta de la extensión del espacio minero y muy especialmente de la mayor capacidad de circulación que -gracias a la expansión ferroviaria-sobre él existía.

\section{Conclusiones}

Como hemos podido constatar, entre los siglos XVIII al XX existió una marcada evolución en la forma como se cartografió el descampado o desierto de Atacama y el territorio de Tarapacá, la que estuvo en consonancia con el desarrollo técnico alcanzado por esta disciplina, pero así también con las orientaciones que fueron adquiriendo progresivamente su misma utilización. Tanto en el período de soberanía peruana como chilena, los mapas o cartas sirvieron para construir un imaginario colectivo sobre estos territorios, pero también para imponer en ellos sistemas económicos específicos, sobre todo el modo de producción capitalista, mismo que a lo largo del período revisado experimentó grandes transformaciones en su mayor capacidad de modificar la zona en un territorio cada vez más capitalizado.

Esta primera aproximación, permite afianzar la estrecha vinculación -ya destacada por la historiografía- respecto a la centralidad que crecientemente fueron adquiriendo estos antiguos territorios marginales, los que una vez conocidos por sus riquezas pasaron a ser priorizados en su dominio y apropiación, tanto por los Estados nación que directamente los disputaron, como por las áreas centrales de la acumulación capitalista, las que se involucraron activamente en la apropiación y utilización económica del espacio salitrero.

El primer período de reconocimiento y representación territorial en ese espacio -agreste pero lleno de riquezas- se dio a fines del siglo XVIII y durante las primeras décadas del XIX, pero sobre todo en estas últimas, donde, tanto la república del Perú como cartógrafos extranjeros, llevaron a cabo la producción de mapas que permitieron posteriormente el progresivo avance del Estado nacional en ese territorio, fenómeno que se repitió de forma ampliada luego en el caso chileno tras la Guerra del Pacífico, cuando se anexaron Tacna, Tarapacá y Antofagasta. En estos mapas, lo principal fue, por supuesto, las referencias a los límites existentes entre las nuevas repúblicas, y también puntos importantes como pueblos, puertos y caminos, además de la costa, dejando de lado elementos más específicos. 
La especificidad económica al interior de los mapas y cartas se dio principalmente desde la segunda mitad del siglo XIX, cuando tanto Perú como Chile comenzaron a complejizar en sus mapas la presencia simbólica de los ríos, yacimientos mineros, puertos de embarque, ferrocarriles, pueblos de cabecera y pueblos-estación, rutas camineras y comerciales, pasos fronterizos, espacios industrializados, etcétera, proceso que se profundizó con la expansión del ciclo de producción salitrera, sobre todo en Tarapacá.

En ese sentido, la intencionalidad fue retratar en un tiempo y espacio determinado aquello que se estaba produciendo en el desierto: el ciclo salitrero a través de la profundización de los modos de producción capitalista, la migración constante de mano de obra, el crecimiento de los establecimientos salitreros de carácter industrial, el crecimiento del ferrocarril como medio preferente de conexión entre puerto y pampa, la circulación de bienes y servicios, es decir, la activación de dinámicas de producción nunca antes vistas en ese territorio.

\section{Referencias citadas}

\section{Bibliografía}

Aguilar, José. 1967. Historia de la cartografía: la tierra de papel, Buenos Aires, Codex.

Aliste Salvo, Valentina. 2014. "Develando el territorio para la nación: el saber geográfico como herramienta de control, racionalización y ocupación del territorio mapuche en el siglo XIX", en Boletín Electrónico de Geografía (BeGEO), № 2, Instituto de Geografía, Facultad de Historia, Geografía y Ciencia Política, Santiago, pp. 1-17.

Arellano, Nelson. 2017. "El desierto de Atacama como laboratorio: experimentos y tecnologías de la energía solar", en Revista Mundo, Vol. 22, № 44, San Cristóbal, pp. 81-89.

Arrowsmith, Aaron \& Lewis, Samuel. 1812. Viceroyalty of Perú. En A new and elegant general atlas, comprising all the new discoveries, to the present time, Boston, Thomas and Andrews.

Artaza, Pablo. 2018. "La producción social del espacio salitrero tarapaqueño durante el ciclo de expansión: entre la necesidad patronal de control social y la resistencia de la sociedad pampina", en Tiempo Histórico, № 17, Santiago, pp. 47-84.

Artaza, Pablo. 2018. "Los cantones salitreros como espacio de tránsito y circulación. Tarapacá durante el ciclo de expansión del salitre”, en Revista Chilena de Antropología, № 37, Santiago, pp. 164-182.

Artaza, Pablo, Lizama, Diego y Sandoval, Ivo. 2021. "Producción del espacio, cartografía y relaciones sociales: Tarapacá y Antofagasta durante el ciclo salitrero (1892-1929)", en Diálogo Andino, № 66. Arica.

Baber, Zaheer. 2001. "Colonizing nature: scientific knowledge, colonial power and the incorporation of India into the modern world system", en British Journal of Sociology, Vol. 52, № 1, Londres, pp. 3758.

Bassols, Ángel. 1979. Geografía, subdesarrollo y regionalización, México, Nuestro Tiempo.

Beckert, Sven. 2015. El imperio del algodón. Una historia global, Barcelona, Crítica. 
Beltrán, Santos. 2013. "Espacio y capitalismo: la crisis capitalista, el territorio y las resistencias sociales", en Ciencia Política, Vol. 8, № 16, Bogotá, pp. 138-167.

Bertrand, Alejandro. 1879. Noticias del Departamento Litoral de Tarapacá y sus recursos, Santiago, Imprenta Nacional.

Bertrand, Alejandro. 2013. Memoria acerca de la condición actual de la propiedad salitrera en Chile, Santiago, Pontificia Universidad Católica de Chile, Cámara Chilena de la Construcción, DIBAM.

Bollaert, William. 1975. "Descripción de la provincia de Tarapacá", en Norte Grande, Vol. 1, № 3-4, Santiago, pp. 461-479.

Bromsen, Maury. 1969. José Toribio Medina, humanista de América, Santiago, Editorial Andrés Bello.

Carmagnani, Marcello. 1998. Desarrollo industrial y subdesarrollo económico. El caso chileno (18601920), Santiago, DIBAM, Departamento de Ciencias Históricas de la Universidad de Chile, Centro de Investigación Diego Barros Arana.

Contreras, Carlos. 2013. "Transferencia de tecnologías e Imperio. El caso de la minería andina en el siglo XVIII", en Diálogo Andino, № 33, Arica, pp. 29-42.

Carrascal, Irma. 2007. Metodología para el análisis de mapas. Temas seleccionados de Geografía de México, México, Instituto de Geografía UNAM.

Castro, Luis, Figueroa, Carolina, Guerrero, Pablo y Silva, Benjamín. 2017. "William Bollaert y sus descripciones geográficas, cartográficas y antropológicas sobre la provincia de Tarapacá en la etapa inicial de la formación republicana del Perú, 1827-1854", en HISTOReLo Revista de Historia Regional y Local, Vol. 9, № 18, Medellín, pp. 123-163.

Centner, Charles W. 1942. "Great Britain and chilean mining. 1830-1914", en The Economic History Rewiev, Vol. 12, № 1/2, Londres, pp. 76-82.

Crespo, Antonio y Fernández, Alberto. 2011. "¿Cartografía antigua o Cartografía Histórica?", en Estudios Geográficos, Vol. LXXII, № 271, Madrid, pp. 403-420.

Crozier, Ronald. 1996. "William Bollaert, explorador y publicista", en Boletín de la Academia Chilena de la Historia, № 106, Santiago, pp. 205-250.

Delgado Mahecha, Ovidio. 2003. Debates sobre espacio en la geografía contemporánea, Bogotá, Universidad Nacional de Colombia.

Dos Santos, Theotonio. 2002. La teoría de la dependencia. Balance y perspectivas, México, Plaza y Janés.

Dym, Jordana. 2010. "Presentación: Mapeando patrias chicas y patrias grandes: cartografía e historia iberoamericana, siglos XVIII-XX", en Araucaria. Revista Iberoamericana de Filosofía, Política y Humanidades, № 24, Sevilla, pp. 99-109.

Fernando Navarro y Sandra Fernández. 2001. "Viajes y viajeros: sobre algunos tópicos para entender la mirada cultural sobre la economía regional argentina", en Theomai, № 3, Buenos Aires, pp. 1-10.

Galaz-Mandakovic, Damir. 2019. Movimientos, tensiones y luces. Historias tocopillanas, Tocopilla, Ediciones Bahía Algodonales. 
Godoy, Milton. 2018. “¿Un gigante con pies de barro? Estado y región en Chile: Atacama meridional (Taltal), 1850-1900", en Godoy, Milton, La puerta del desierto: Estado y región en Atacama. Taltal, 1850-1900, Santiago, Ed. Mutante, pp. 43-88.

González, José. 2007. "Primeros levantamientos cartográficos generales de Chile con base científica: los mapas de Claudio Gay y Amado Pissis", en Revista de Geografía del Norte Grande, № 38, Antofagasta, pp. 21-44.

González, Sergio. 2009. "El Norte Grande de Chile: la definición histórica de sus límites, zonas de líneas de fronteras, y la importancia de las ciudades como geosímbolos fronterizos", en Revista de Historia Social y de las Mentalidades, Vol. 13, № 2, Santiago, pp. 1-25.

González, Sergio. 2013. "Alejandro Bertrand Huillard (1854-1942)”, en Bertrand, Alejandro. Memoria acerca de la condición actual de la propiedad salitrera en Chile, Santiago, Pontificia Universidad Católica de Chile, Cámara Chilena de la Construcción, DIBAM, pp. IX-LVIII.

González, Sergio. 2013. "Del descampado de Atacama a la Sociedad del Salitre. Balance y perspectiva en el estudio del ciclo de expansión del nitrato", en González, Sergio (comp.), La Sociedad del Salitre. Protagonistas, migrantes, cultura urbana y espacios públicos, 1870-1940, Santiago, Ril Editores, pp. 23-37.

González, Sergio. 2013. "Heterotopía y utopía en la pampa salitrera. Desde los mitos de la ocupación del desierto y del descubrimiento del salitre a la urbanización de la pampa, 1870-1920", en González, Sergio (comp.), La Sociedad del Salitre. Protagonistas, migrantes, cultura urbana y espacios públicos, 1870-1940, Santiago, Ril Editores, pp. 215-238.

González, Sergio y Artaza, Pablo. 2013. "El concepto de cantón salitrero y su funcionalidad social, territorial y administrativa: los casos de Zapiga, Lagunas y El Toco", en González, Sergio (comp.), La Sociedad del Salitre. Protagonistas, migrantes, cultura urbana y espacios públicos, 1870-1940, Santiago, Ril Editores, pp. 325-265.

González, Sergio y Godoy, Milton. 2013. "Norte Grande y Norte Chico: construcción social de un imaginario compartido, 1860-1930", en González, Sergio (comp.), La Sociedad del Salitre. Protagonistas, migrantes, cultura urbana y espacios públicos, 1870-1940, Santiago, Ril Editores, pp. 195-213.

Harley, J. B. 2005. La nueva naturaleza de los mapas. Ensayos sobre la historia de la cartografía, México, Fondo de Cultura Económica.

Harvey, David. 2007. Espacios del capital. Hacia una geografía crítica, Madrid, Akal Ediciones.

Hidalgo, Jorge. 2009. "Civilización y fomento: la "descripción de Tarapacá" de Antonio O’Brien, 1765", en Chungará, Vol. 41, № 1, Arica, pp. 5-44.

Instituto Geográfico Militar. 1952. Cartografía hispano colonial de Chile. Il atlas: homenaje del Ejército de Chile a José T. Medina, Santiago, Instituto Geográfico Militar.

Llanos, Claudio. 2011. "Pueblos y paisajes en la royal society de Londres. Las ciencias humanas y el imperialismo británico. (1860-1914)”, en História, Vol. 30, № 1, Sao Paulo, pp. 306-331.

Llanos, Claudio y González, José Antonio. 2014. "Riquezas y rutas. El sur de Chile en la mirada científica imperial británica. (1830-1870)”, en Uistória Unisinos, Vol. 18, №. 1, Janeiro, pp. 44-55. 
Lefebvre, Henri. 1974. "La producción del espacio”, en Papers. Revista de Sociología, № 3, Barcelona, pp. 219-229.

Levinas, Marcelo y Vidal, Silvina. 2016. "La cosmografía de Waldseemüller, la conceptualización de "América" y su relación con el copernicanismo", en Scientiae Studia, Vol. 14, № 2, Sao Paulo, pp. 281331.

Marchioni, Marco. 2013. "Espacio, territorio y procesos comunitarios", en Revista Espacios Transnacionales, № 1, México, pp. 92-100.

Mayo, John. 1981. "Britain and Chile. Anatomy of a relationship", en Journal of Interamerican studies and world and affairs, Vol. 23, № 1, Londres, pp. 95-120.

Medina, José Toribio. 1889. Ensayo acerca de una mapoteca chilena o sea de una colección de los títulos de los mapas, planos y vistas relativos á Chile arreglados cronológicamente: con una introducción histórica acerca de la geografía y cartografía del pais, Santiago, Ercilla.

Molinari, Diego. 1941. El nacimiento del nuevo mundo: 1492-1534, historia y cartografía, Buenos Aires, Kapeluz.

Morales, Héctor, Richard, Nicolás y Garcés, Alejandro. 2018. “Capitalismo en el desierto: materialidades, espacios y movimiento", en Revista Chilena de Antropología, Universidad de Chile, N37, Santiago, pp. 76-82.

Núñez, Andrés, Zambra, Antonia y Aliste, Enrique. 2017. "El poder de los mapas. los mapas de poder: la construcción del saber geográfico de Patagonia-Aysén", en Universum, Vol. 32, № 2, Talca, pp. 149162.

Ortega, Luis. 2005. Chile en ruta al capitalismo: cambio, euforia y depresión 1850-1880, Santiago, LOM.

Palladino, Paolo y Wordboys, Michael. 1993. "Science and Imperialism", en Isis, Vol. 84, № 1, Chicago, pp. 91-102.

Paz Soldán, Mariano. 1862. Geografía del Perú, Lima, Imprenta Liberal.

Paz Soldán, Mariano. 1878. Verdaderos límites entre Perú y Bolivia, Lima, Imprenta Liberal.

Pfeilstetter, R. 2011. "El territorio como sistema social autopoiético. Pensando en alternativas teóricas al 'espacio administrativo' y a la 'comunidad local'", en Perifèria: revista de recerca i formació en antropología, № 14, Barcelona, pp. 1-17.

Pinto, Julio. 1997. Episodios de historia minera: estudios de historia social y económica de la minería chilena, siglos XVIII-XIX, Santiago, Universidad de Santiago.

Rosenblitt, Jaime y Sanhueza, Mạ Carolina. 2010. Cartografía histórica de Chile, 1778-1929, Santiago, Cámara Chilena de la Construcción, Pontificia Universidad Católica de Chile, DIBAM.

Sagredo, Rafael. 2018. J. T. Medina y su biblioteca americana en el siglo XXI: prácticas de un erudito, Santiago, DIBAM.

Sosa Velázquez, Mario. 2012. ¿Cómo entender el territorio?, Guatemala, Cara Parens.

Saldivia, Zenobio. 2005. La Ciencia en el Chile Decimonónico, Santiago, Ediciones Universidad Tecnológica Metropolitana.

Santos, Milton. 2000. La naturaleza del espacio, Barcelona, Editorial Ariel. 
Sluyter, Andrew. 2001. "Colonialism and Landscape in the Americas: Material/Conceptual Transformations and Continuing Consequences", en Annals of the Association of American Geographers, Vol. 91, № 2, Londres, pp. 410-428.

Thompson, Andrew. 1992. "An exploration in the history of Anglo-Argentine relations, 1810-1914", en Journal of Latin American Studies, Vol. 24, № 2, Londres. pp. 419-436.

Turner, Frank M. 1980. “Public Science in Britain, 1880-1919”, en Isis, Vol. 71, № 4, Chicago, pp. 589-608.

Uricoechea, Ezequiel. 1860. Mapoteca colombiana: Colección de los títulos de todos los mapas, planos, vistas, etc. relativos á la América española, Brasil é islas adyacentes, Londres, Trübner \& Cie.

Valencia, Germán. 2011. "Teoría económica y formación del Estado nación: mercantilistas y liberalistas", en Ecos de Economía, Vol. 15, № 32, Medellín, pp. 1-23.

Vega, Alejandra. 2014. Los Andes y el territorio de Chile en el siglo XVI. Descripción, reconocimiento e invención, Santiago, DIBAM, Centro de Investigaciones Barros Arana.

Vicuña Mackenna, Benjamín. 1882. El libro de la plata, Santiago, Imprenta Cervantes.

Villalobos, Sergio. 1979. La economía de un desierto: Tarapacá durante la Colonia, Santiago, Ediciones Nueva Universidad.

Wallerstein, Immanuel. 2014. El capitalismo histórico, Madrid, Siglo XXI.

Zarrilli, Adrián. 2002. "Transformación ecológica y precariedad económica en una economía marginal. El gran Chaco argentino, 1890-1950", en Theomai, № 1, Buenos Aires, pp. 1-14.

\section{Mapas, cartas y planos}

Amadée Frezier. 1712. "Copia del plano topográfico del Puerto del Callao". Mapoteca de Sala Medina de la Biblioteca Nacional de Chile, Santiago, pp. 4-19.

Bertrand, Alejandro. 1879. "Territorio ocupado en Tarapacá por el Ejército Chileno". Mapoteca de la Biblioteca Nacional de Chile. Disponible en: http://www.memoriachilena.gob.cl/602/w3-article86799.html (Consultado en abril-mayo de 2020).

Daniel Barrera. 1871. "Mapa del Perú", Disponible en: https://www.idepe.org.pe/singlepost/2018/09/22/Peru-Mapa-de-1871-por-Daniel-Barrera. (Consultado el 22 de abril de 2020).

Delegación Fiscal de Salitreras. 1896. "Plano de la Región salitrera desde Arica a Tocopilla", litografiado por J. Méndez. Solicitud de digitalización a la Mapoteca de la Biblioteca Nacional. Disponible en: http://www.bibliotecanacionaldigital.gob.cl/visor/BND:355395 (Consultado en abril-mayo de 2020).

Delegación Fiscal de Salitrera. 1910. “Carta de la rejión salitrera comprendida entre los paralelos $19^{\circ}$ y $27^{\circ} 30^{\prime}$ Lat. Sur". Consultado en Biblioteca Nacional Digital, Disponible en: http://www.bibliotecanacionaldigital.gob.cl/visor/BND:347817. (Consultado en abril de 2020).

Departamento de Obras Públicas, Dirección de Ferrocarriles. 1929. "Ferrocarriles de Chile". Consultado en Biblioteca Nacional Digital. Disponible en: http://www.bibliotecanacionaldigital.gob.cl/visor/BND:156653 (Consultado en abril-mayo de 2020). 
Riso Patrón, Luis. 1910. "Mapa de Chile. Ejecutado por orden de S.E. el Presidente de la Republica Exmo. Sr. D. Pedro Montt. Ed. Centenario". Consultado em Biblioteca Nacional Digital. Disponible en: http://www.bibliotecanacionaldigital.gob.cl/visor/BND:331550 (Consultado en abril-mayo de 2020).

Castro, Luis (et al.). 2017. "William Bollaert y sus descripciones geográficas, cartográficas y antropológicas sobre la provincia de Tarapacá en la etapa inicial de la formación republicana del Perú, 1827-1854", en HistoReLo. Revista de historia regional y local, Vol. 9, № 18, Medellín, pp. 121-164. Disponible en: https://dialnet.unirioja.es/servlet/articulo?codigo=6050558 (Consultado abril-mayo de 2020). 